\title{
Decision support method for early-phase design of offshore hydrocarbon fields using model-based optimization
}

\author{
Diana González ${ }^{1}$ [D $\cdot$ Milan Stanko ${ }^{1} \cdot$ Arnaud Hoffmann ${ }^{2}$
}

Received: 25 March 2019 / Accepted: 24 November 2019 / Published online: 4 December 2019

(c) The Author(s) 2019

\begin{abstract}
This paper presents the development of a method to provide decision support in the feasibility studies and concept planning phases of oil and gas field development. The objective in developing the methodology was to provide an easy-to-use facility to integrate the production-governing elements of oil and gas fields that capture the integrated production and economic performance of the system. This in a modular and scalable manner includes numerical optimization and uncertainty analyses needed to support engineering decisions. The method follows a series of steps that allow determining the optimal field production profile, drilling schedule, type of offshore structure, pressure support method and selection of artificial lift. The first step consists of creating efficient (low running time) proxy models of the production performance of the field and the costs figures associated with the project. The proxy model of the production performance is based on curves of maximum production rates versus cumulative production and contains all relevant field design features and computation of the most relevant performance indicators to consider in the evaluation. The proxy model to estimate the costs associated with the project is based on linear equations function of production rates and number of wells. The second step is to perform numerical optimization to find optimal production profile and drilling schedule that maximize the net present value of the specific development strategies considered. For the last step, an evaluation of the effect of uncertainties on the results of the numerical optimization using probabilistic methods is performed. The method was applied in a synthetic production system based on public data of Wisting field (currently under development). The field is a remote low-energy oil reservoir located in the Barents Sea. Nine strategies, obtained from the combination of three recovery support methods and three processing facilities, were compared using the net present value as decision factor. The best strategy consists of using a tension leg platform as processing facility and multiphase boosting plus water injection as recovery support method. This strategy generated the highest production and required the lowest costs, resulting in the highest profitability. It was demonstrated that the methodology successfully finds optimal field design features while quantifying the effect of uncertainties.
\end{abstract}

Keywords Field development planning $\cdot$ Optimization $\cdot$ Proxy model $\cdot$ Uncertainty analysis $\cdot$ Mixed-integer linear programming

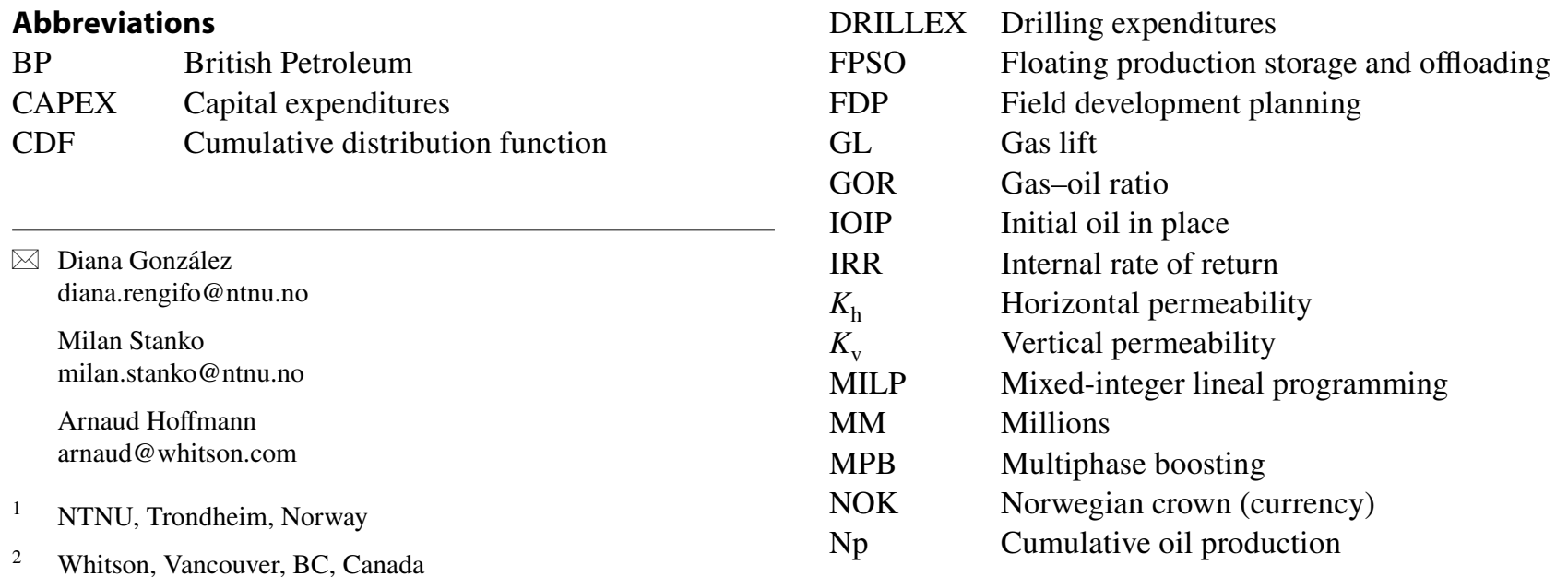

Whitson, Vancouver, BC, Canada 


$\begin{array}{ll}\text { NPV } & \text { Net present value } \\ \text { Nw } & \text { Number of wells } \\ \text { OPEX } & \text { Operating expenditures } \\ P & \text { Probability } \\ \text { PI } & \text { Productivity index } \\ P V T & \text { Pressure, volume, temperature } \\ \text { RAM } & \text { Random access memory } \\ \text { SOS } & \text { Special ordered set } \\ \text { stb } & \text { Stock tank barrel } \\ \text { scf } & \text { Standard cubic feet } \\ \text { TLP } & \text { Tension leg platform } \\ \text { USD } & \text { United State dollar } \\ \text { WC } & \text { Water cut } \\ \text { WI } & \text { Water injection } \\ \text { kW } & \text { Kilo Watts }\end{array}$

\section{Introduction}

Field development is a crucial stage in the life of a hydrocarbon field, when the plans for the future exploitation of the asset take place. The purpose of field development planning (FDP) is to identify the best strategy to exploit an asset by finding the concepts that are technically feasible and provide the best economic performance. A typical field development process is divided into three main phases:

1. Identification of business case: pre-exploration, and exploration and appraisal.

2. Project planning: feasibility studies, concept planning and pre-engineering.

3. Project execution: detailed engineering and construction.

This paper focuses on the technical evaluation that occurs during the early phases of project planning, in particular feasibility studies and concept planning. To perform these tasks, typically a value chain model is established by the field design team. This value chain model includes all information available about the system, but it also includes all the main design features of the field that are considered, such as well type, reservoir pressure support strategy, production scheduling, platform type and production system layout.

The evaluation of each field development strategy is done considering a variety of issues ranging from geopolitics, corporate strategy, technical constraints, project cost, operational flexibility and scalability, operating and financial risks, among others. However, one of the main factors that is often used to compare alternatives is the project cost, often represented by indicators such as net present value (NPV) or internal rate of return (IRR). The project cost is affected by most elements of the value chain model, e.g., the production profile, oil price, type of surface facilities, platform type, tax regime, etc.
The use of optimization to help the decision process during field development could allow finding, in an automated and robust manner, the best field configuration based on certain requirements or constraints. Several studies exist in the literature that use optimization to improve field development, by finding the optimal configuration of parameters like well characteristics, drilling program, production and injection strategies, etc., to maximize the economic outcomes or the oil/gas recovery. Many of these studies (Jonsbråten 1998; Túpac et al. 2007; Bellout et al. 2012; Simonov et al. 2019) depend on complex reservoir models to represent the production system performance, but in early phases of FDP, complex reservoir models are typically not available. In addition, by using reservoir models only, these studies are not considering the effect of the backpressure of wells and network systems on the sand face when computing production profiles and this can lead to significant errors. On the other hand, other studies (Storvold 2012) used a multiphase flow simulator of the production system to generate data that are later used in the optimization. In such cases, the effect of reservoir decline and depletion on the production system is not captured accurately and this can lead to errors or a poor representation of the production performance. Other authors (Nazarian 2002; Litvak et al. 2007; Volz et al. 2008; Litvak and Angert 2009; Litvak et al. 2011; Silva et al. 2019) have used a more realistic representation of the production system by integrating models of subsurface and surface facilities, improving their capability to represent the performance of the field. Regarding the optimization workflow used by these studies, in general, complex models that are usually difficult to set up and required considerable computational power, require also complex optimization methods that are time-consuming and need considerable time to set up. For example, stochastic mixed-integer problems were used in the work of Jonsbråten (1998), nonlinear optimization in the work of Bellout et al. (2012) and Silva et al. (2019) or genetic algorithms in the works of Nazarian (2002), Túpac et al. (2007) and Litvak et al. (2007).

In early field development, uncertainties associated with the reservoir characteristics, costs, future oil price, etc., are big. For this reason, it is important to consider the effect of uncertainties when planning the future exploitation of a field. Some of the studies previously mentioned do not consider uncertainties when optimizing the field development process (Túpac et al. 2007; Storvold 2012; Simonov et al. 2019). On the other hand, Litvak et al. (2007), Litvak and Angert (2009) and Litvak et al. (2011) made use of BP's Top-Down Reservoir Modeling method (Williams et al. 2004) to perform optimization during field development while including uncertainty analysis with uncertainty in the reservoir. Jonsbråten (1998) performed stochastic optimization considering uncertainty in the oil price, which resulted in complex optimization problems. 
Accurately estimating costs during early field development is especially difficult since detailed specifications of the production system components are needed and might not be available at this stage. Moreover, if the design conditions are changed, it takes considerable time and effort to compute the updated cost figures. A possible alternative is to generate parametric estimation of costs, which consists of models based on previous projects and historical cost figures. The literature presents several works (Karlik 1991; Jablonowski and Strachan 2008; Kuznetsov et al. 2011; Nunes et al. 2017; Nunes et al. 2018), which used standard regression analysis of cost data to generate equations that fit these data and allow performing predictive estimations of costs.

As shown above, techniques like optimization, uncertainty analysis and cost estimation models have been used to support the decision process during field development with a varying degree of model complexity, model execution and methods. However, the differentiating characteristics and contributions of the present research are as follows:

- Extension of the well potential concept used in reservoir engineering to an integrated production system including reservoir, inflow, flow in wellbore and well in gathering network, and considering the presence of adjustable equipment such as chokes and artificial lift equipment. This concept allows to build a proxy model to estimate field production profiles suitable for systems where the reservoir is represented by a tank and the wells in the network are produced from a single reservoir unit.

- Formulation of the NPV optimization as a mixed-integer linear problem using SOS2 models. This allows the optimization problem to be solved with low running times, suitable for extensive sensitivity studies, and it guarantees global optimality. Additionally, it allows to use results of more complex models directly in the optimization as a collection of points on a table rather than requiring the live run of simulators and models in the optimization or developing approximations based on simplified mechanistic equations.

- Development of a method to advice field planners during early-phase development that has low running time and average computing power requirements. The method is suitable for extensive probabilistic evaluations that consider first-order interactions between elements in the field value chain and captures the interdependency between reservoir and production system.

- The method is intended for the field development phases where the information about the subsurface is scarce and uncertain, and complex subsurface models are under development.

This paper presents the development of an automated methodology that uses optimization in field development planning to determine the best production strategy for a field. The methodology is based on:

- Development of proxy models of the production performance of field and the cost figures associated with the project. The proxy model of the production performance is based on the concept of production potential used in reservoir engineering. These models are used to reduce complexity and decrease the computational time when performing optimization.

- Development of a numerical optimization problem to maximize NPV as a function of production and drilling schedule. The optimization is formulated as a mixedinteger linear problem.

- Evaluation of the effect of uncertainties such as cost values, reservoir size, well productivity and layout of the production system, using probability trees.

The methodology was tested on a synthetic case based on publicly available data of the Wisting field, which is currently under development. The Wisting field has low pressure, low temperature and low gas-oil ratio (GOR), and it is in a remote location in the Barents Sea, $400 \mathrm{~km}$ from shore.

\section{Development of the proxy model to compute the production performance of the integrated production system}

The production performance of the production system is represented by production potential curves. The curves are tables of maximum oil production rates, producing GOR and water cut (WC) as function of the cumulative oil production (Np) and number of wells $(\mathrm{Nw})$. These proxy models are used to estimate field production when the production schedule is varied without needing to repeatedly run simulation models of reservoir and production network. To generate the production potential curves, a reservoir model and a production network model must be coupled and the simulation must be run to obtain the maximum production that the field can deliver.

In this work, the reservoir model employed is a tank model and the wells/production system is represented in a steady-state multiphase network model. To integrate both models, yearly data on reservoir pressure, WC and GOR, taken from the reservoir model, are used as input parameters in the network model. To compute the production potential, the maximum production possible must be estimated assuming no choke or any kind of flow restriction in the system. The effect of artificial lift methods and improved oil recovery methods, such as gas lift and multiphase boosting, should be included when computing the production potential. 
In this work, all wells in the production network model were considered equal. The authors believe this is a valid simplification during early phases of field development when there is, often, little information on the characteristics of the reservoir.

Once the models have been integrated, curves of oil production potential, GOR and WC rates, as function of number of wells and cumulative oil produced, are computed. Figure 1 shows an example of an oil production potential family of curves.

The curve of production potential versus cumulative production can be used to plan the production scheduling of a field without the need to perform runs of integrated reservoir and network models. One approach to do so could be the following:

- Define a time step, $\mathrm{d} t$

- At time $t$, with the cumulative oil production, find in the production potential curve the maximum rate that the system can produce

- If the desired field target rate is higher than the potential, then produce at potential, if not, produce the field target rate

- Proceed to time $t_{i+1}$. Estimate the new cumulative production and repeat from step 2 .

There might be variations of this procedure depending if cumulative production is estimated explicitly or implicitly.

\section{Development of the proxy models of the cost}

The costs considered for the estimation of the net present value in this work are capital, drilling and operating expenditures (CAPEX, DRILLEX and OPEX). Neither the abandonment cost nor the taxes and royalties were taken into account. In general, cost estimation requires a significant amount of input and is a labor- and time-intensive manual process. The strategy used in this research is to use

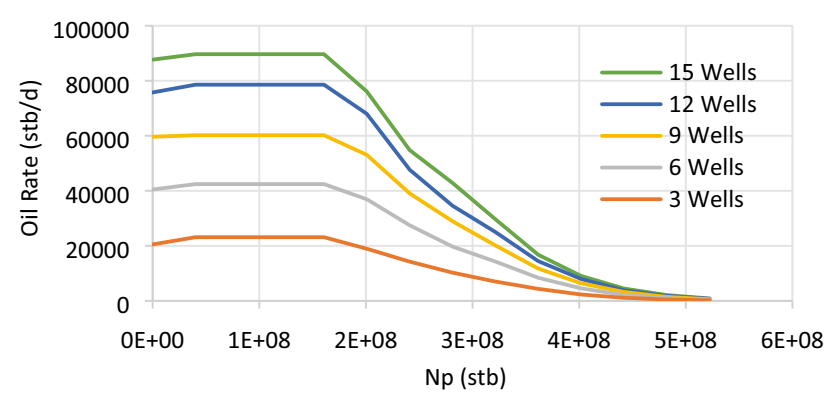

Fig. 1 Example of proxy model for oil production potential simplified cost models based on equations that capture the first-order effect of the field design features under study on the cost figures. This type of models is suitable for numerical optimization schemes or analysis of uncertainty where the input must be varied several times in an iterative process.

In this work, the costs are expressed as function of the capacity of the processing facility (this is, maximum oil, gas and water rates that can be processed) and the number of production and injection wells in the field. The proxy models consist of linear equations, created from a multivariable linear regression, of CAPEX, OPEX and DRILLEX data as function of the mentioned variables. This resulted in equations of the form:

$$
\begin{aligned}
E_{\text {capex }}= & a_{\text {cap }} \cdot q_{o}^{\text {capacity }}+b_{\text {cap }} \cdot q_{g}^{\text {capacity }} \\
& +c_{\text {cap }} \cdot q_{w}^{\text {capacity }}+d_{\text {cap }} \cdot \mathrm{Nw}^{\text {field }}+e_{\text {cap }} \\
E_{\text {opex }}= & a_{\text {op }} \cdot q_{o}^{\text {capacity }}+b_{\mathrm{op}} \cdot q_{g}^{\text {capacity }} \\
& +c_{\text {op }} \cdot q_{w}^{\text {capacity }}+d_{\text {op }} \cdot \mathrm{Nw}^{\text {field }}+e_{\mathrm{op}} \\
E_{\text {drillex }}= & a_{\text {drill }} \cdot \mathrm{Nw}_{d, p+i}^{j}+b_{\text {drill }}
\end{aligned}
$$

In Eqs. (1) and (2), $q_{o}^{\text {capacity }}$ and $q_{w}^{\text {capacity }}$ are expressed in units of stb/d and $q_{g}^{\text {capacity }}$ is given in MM scf/d.

\section{Estimation of net present value}

The net present value is the indicator used in this work to decide the optimum production profile and drilling schedule. The NPV is the difference between the present value of cash inflow, represented by the revenues from hydrocarbon sells, and the present value of the cash outflow, represented by the costs, over a period. This economic indicator is commonly used in field development to analyze the profitability of a project. Equation (4) shows the formula of the NPV used in this methodology.

$\mathrm{NPV}=\sum_{j=0}^{N} \frac{\left\{N_{p}^{j} \cdot P_{o}^{j}\right\}-\left\{E_{\text {capex }}^{j}+E_{\text {opex }}^{j}+E_{\text {drillex }}^{j}\right\}}{(1+\mathrm{DR})^{j}}$

where $j$ : index of time, $N$ : total number of years, DR: discount rate $(\%), N_{p}^{j}$ : cumulative oil produced in a period (stb), $P_{o}^{j}$ : price of oil $(\mathrm{NOK} / \mathrm{stb}), E_{\text {capex }}$ : CAPEX (MM NOK), $E_{\text {opex }}$ : OPEX (MM NOK), $E_{\text {drillex }}$ : DRILLEX (MM NOK). 


\section{Optimization}

Numerical optimization is used to determine the optimum oil production and drilling schedules that give maximum NPV at the end of the life of a field for a specific development scenario.

The objective function is to maximize the net present value of the production system

\section{$\operatorname{maxNPV}$}

by changing the oil production rates per year, $q_{o}^{j}$, and the number of new producing wells drilled in each time step, $\mathrm{Nw}_{\text {drilled }}^{j}$.

The optimization problem is subject to the following constraints: $\forall j \in\{1,2, \ldots N\}$,

$q_{o}^{j} \leq q_{o, \text { pot }}^{j}$

$\mathrm{Nw}_{\text {drilled }}^{\min } \leq \mathrm{Nw}_{\text {drilled }}^{j} \leq \mathrm{Nw}_{\text {drilled }}^{\max }$

where $q_{o, \text { pot }}^{j}$ is the potential oil rate at time step $j . \mathrm{Nw}_{\text {drilled }}^{\min }$ and $\mathrm{Nw}_{\mathrm{drilled}}^{\text {max }}$ represent the minimum and maximum number of wells that can be drilled in each time step, respectively.

The potential oil rate is a nonlinear function of the cumulative oil produced, $\mathrm{Np}^{j}$, and the number of production wells in the field, $\mathrm{Nw}^{j}$ :

$q_{o, \text { pot }}=q_{o, \text { pot }}(\mathrm{Np}, \mathrm{Nw})$

Additional operational constraints consist of a maximum oil rate, $q_{o, \text { erosion }}^{\max }$, to prevent erosion in the elements of the production system and an injection water rate capacity, $q_{w, \text { inj' }}^{\max }$, when applied:

$q_{o}^{j} \leq q_{o, \text { erosion }}^{\max }$

$q_{w, \text { inj }}^{j} \leq q_{w, \text { inj }}^{\max }$

For field development strategies with water injection, the constraint shown in (10) is included in the optimization formulation. The water injection is calculated as a function of the cumulative water injection, $\mathrm{Wp}_{\mathrm{inj}}^{j}$, obtained from material balance:

$q_{w, \text { inj }}=q_{w, \text { inj }}\left(\mathrm{Wp}_{\text {inj }}\right)$

The costs, used in Eq. (4), depend on the production capacity of the processing facilities, $q_{o}^{\text {capacity }}, q_{g}^{\text {capacity }}$ and $q_{w}^{\text {capacity }}$, and the number of wells in the field:

$E_{\text {cap }}=E_{\text {cap }}\left(q_{o}^{\text {capacity }}, q_{g}^{\text {capacity }}, q_{w}^{\text {capacity }}, \mathrm{Nw}^{\text {field }}\right)$
$E_{\mathrm{op}}=E_{\mathrm{op}}\left(q_{o}^{\text {capacity }}, q_{g}^{\text {capacity }}, q_{w}^{\text {capacity }}, \mathrm{Nw}^{\text {field }}\right)$

$E_{\text {drill }}=E_{\text {drill }}\left(\mathrm{Nw}_{d, p+i}^{j}\right)$

The OPEX is a yearly average, and $\mathrm{Nw}^{\text {field }}$ is the total number of production and injection wells in the field. As mentioned before, the number of injection wells is assumed to be equal to the number of production wells; this means that $\mathrm{Nw}_{d, p+i}^{j}(t)=2 \cdot \mathrm{Nw}_{\text {drilled }}^{j}$.

The production oil, gas and water capacities of the procession facilities and the total number of wells are obtained as follows:

$q_{o}^{\text {capacity }} \geq q_{o}^{j}$

$q_{g}^{\text {capacity }} \geq q_{g}^{j}$

$q_{w}^{\text {capacity }} \geq q_{w}^{j}$

$\mathrm{Nw}^{\text {field }} \geq \mathrm{Nw}^{j}$

where $q_{g}^{j}$ and $q_{w}^{j}$ are the production gas rate and the production water rate of the field for each time step, respectively. The gas rate is a nonlinear function of the oil rate and the GOR and the water rate is a nonlinear function of the oil rate and the WC, both obtained from the proxy models in "Development of the proxy model to compute the production performance of the integrated production system" section.

$q_{g}=q_{o} \cdot \operatorname{GOR}(\mathrm{Np}, \mathrm{Nw})$

$q_{w}=\frac{q_{o} \cdot \mathrm{WC}(\mathrm{Np}, \mathrm{Nw})}{1-\mathrm{WC}(\mathrm{Np}, \mathrm{Nw})}$

\section{Linear reformulation}

The optimization was reformulated as a mixed-integer linear problem (MILP). This means that the objective is a linear function and the constraints are linear equations or inequalities. Variables can be continuous (e.g., production rates) and/ or discrete (e.g., number of wells to drill). The approach used here to solve the MILP formulation is a combination of the simplex algorithm and branch and cut method (IBM 2010). This method uses a branch and bound algorithm with a cutting plane method to tighten the linear programming relaxations. A more detailed explanation of branch and cut algorithm can be found in Grötschel and Holland (1991), Padberg and Rinaldi (1991). 
To reformulate the optimization, special ordered set models of type 2 (SOS2) were used to linearly approach the nonlinear functions in Eqs. (8), (11), (19) and (20). SOS2 is a set of consecutive nonnegative variables, which sum must be equal to one (1) and, at most, two adjacent members can be nonzero in a feasible solution. Note that Eqs. (19) and (20), being bilinear, require some additional manipulations to be included in a MILP. The details of the MILP formulation are presented in "Appendix." For more information about SOS2 models for piecewise linear approximation, refer to Codas et al. (2012), Silva and Camponogara (2014), Hoffmann and Stanko (2017).

\section{Uncertainty analysis}

Uncertainty analysis is used here to study the probable range of NPV values that can be obtained as product of the variation of the following parameters:

- Initial hydrocarbon volume in place.

- Well productivity.

- Costs figures (CAPEX, OPEX, DRILLEX).

- Uncertainty in the layout of the subsea production system.

Probability tree was the method used to quantify the effect of uncertainty. For the uncertainty on the reservoir size, three initial hydrocarbon volumes were used, representing P10, P50 and P90 probabilities. For the well productivity, three values of horizontal and vertical permeability were used in a range of $\pm 20 \%$. The costs were also varied in a range of $\pm 20 \%$, with a total of three costs values used. Different network models were built for three different layouts of the production system. For well productivity, cost figures and uncertainty in the layout of the production system, due to lack of information about their probability, it was considered that all the values used had the same probability.

\section{Study case}

The elements described previously, namely:

- The method to create a proxy model to predict the production performance of the system, based on the production potential concept using a series of pre-computed tables and cost figures.

- The NPV optimization methodology to find optimal production and drilling schedules that maximize NPV.

- Uncertainty evaluation and quantification on the optimization results using probability trees. were used together to define an integrated method to provide decision support to field planners during early phases of field development.

The method is applied to a synthetic case based on publicly available data about the Wisting field. The ultimate goal is to demonstrate the potential of the method and provide observations about performance, applicability and usefulness.

Wisting is an existing prospect that, at the moment of developing this study, was under development stage. Relevant information to model the field, like reservoir model, was not available. Therefore, aside from information available on the public domains, the models have been built based on assumptions or simplifications. For example, material balance was used to model the reservoir, the PVT properties of the fluid were calculated using a black-oil model, and all wells were considered identical in the network model. The methodology was used to compare different field development strategies and determine the best strategy to exploit the synthetic field. The average properties of the field are shown in Table 13 in "Appendix."

\section{Applying the method to the study case}

\section{Step 1: selection of feasible field development strategies}

For the study case, three recovery support methods and three topside facilities were considered. Combined, they give nine field development strategies.

The recovery scenarios used are:

- Gas lifted wells (GL).

- Gas lifted wells + water injection (GL+WI).

- Multiphase boosting + water injection (MPB + WI).

The topside facilities considered are:

- Tension leg platform (TLP).

- Floating production storage and offloading (FPSO).

- Tie-back to existing platform.

Other recovery scenarios, artificial lift methods and topside facilities, were considered less relevant or unrealistic and were therefore not considered. The cases to consider were defined in collaboration with the partners of the SUBPRO research program (SFI SUBPRO 2019).

Creation of models:

- Material balance was used to model the reservoir, using MBAL, a software from Petroleum Experts.

- Network model in PIPESIM. 
- Excel to integrate both and generate production potential tables.

- Cost estimation in AMPL.

- Optimization in AMPL + CPLEX.

- Evaluation of uncertainties using Pipe-It (Petrostreamz 2018).

Assumptions:

- PVT properties of the fluid were calculated using a blackoil model.

- All wells were considered identical in the network model.

\section{Step 2: generation of proxy model of production potential}

For each development strategy, production potential curves displaying oil rate, GOR and WC as function of cumulative oil production and number of wells were generated from the integration of a reservoir model and a well/production system model. The type of topside facilities was not considered during the generation of the production potential profiles since the first-stage separator pressure is kept constant and this eliminates the pressure dependency between the two systems.

The reservoir was modeled in a commercial material balance simulator (Petroleum Experts 2016) as a single oil tank. Black-oil PVT tables were used to model the fluid properties. For the tank's input data, the initial reservoir pressure, initial reservoir temperature and initial oil in place (IOIP) shown in Table 13 were used as initial conditions. The data used to create the reservoir model are shown in Table 14 and Fig. 13 in "Appendix."

To account for the different recovery strategies, two types of reservoir models were built. For the first type, no water injection was considered and the average oil rate was constrained to $110,000 \mathrm{stb} / \mathrm{d}$. In the second type, the same average oil rate was used and water injection was implemented with a voidage replacement factor of $100 \%$.

The wells/production network calculations were performed in a commercial steady-state software (Schlumberger 2012a). Here, to account the influence of the number of wells, six models were built each with different amounts of production wells (1, 3, 6, 9, 12 and 15 wells). All wells

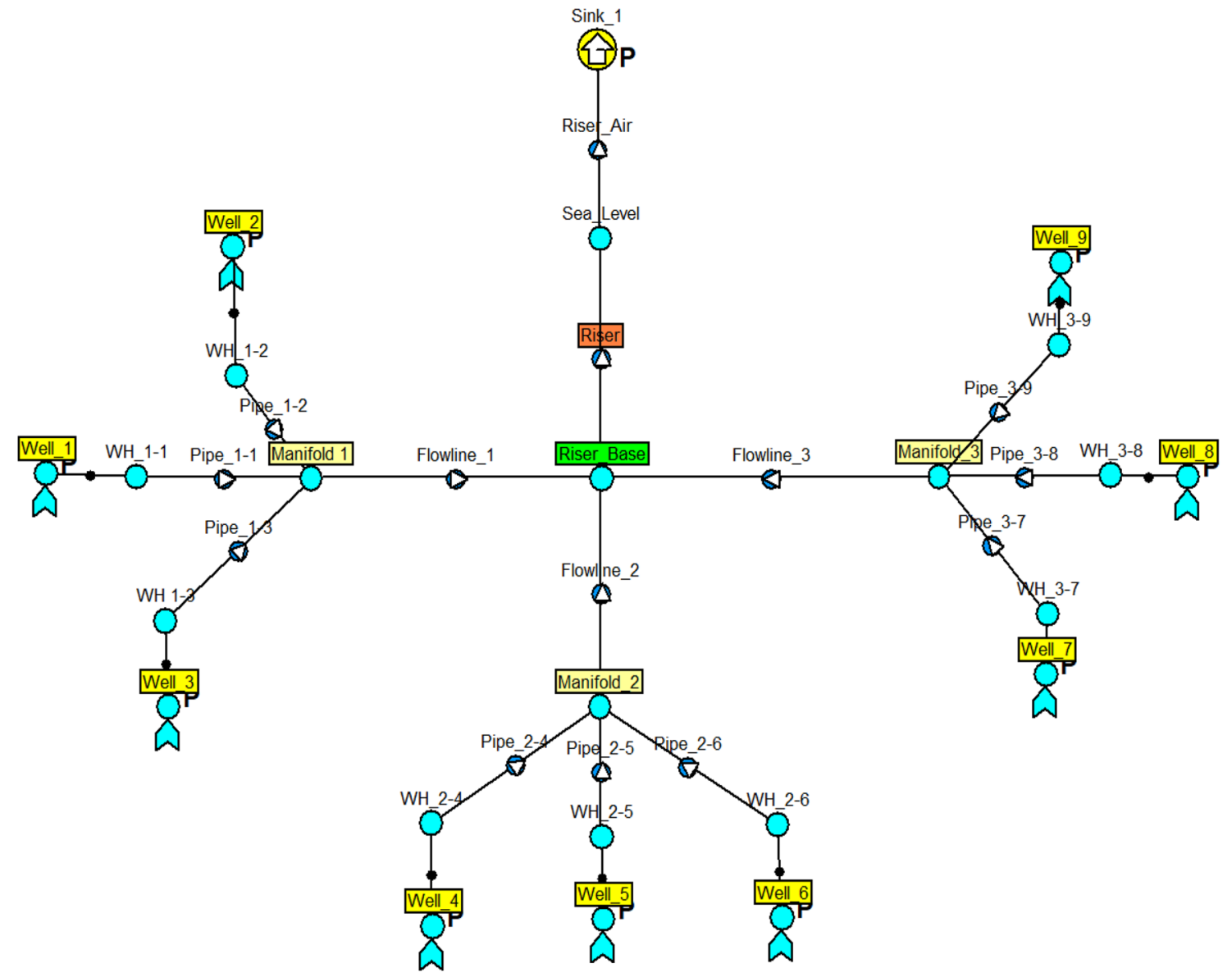

Fig. 2 Production system layout 
were assumed identical. The production wells are horizontal, and no wellhead chokes were included. The layout of the well/production network consists of 3-well clusters producing into flowlines. The production of the flowlines is commingled at the base of a riser. The riser has an elevation of $480 \mathrm{~m}$ and is followed by a sink, which represents the end of the system, located $30 \mathrm{~m}$ above the sea level. Figure 2 shows a representation of the production system layout used. To compute the productivity index of the wells, Joshi's model for steady-state horizontal well productivity was used (Joshi 1991). For this, reservoir size was assumed equal to the one used by Yadigarov (2017). The fluid properties were modeled with a black-oil model, using the same black-oil tables used in the reservoir model. For the boundary conditions, a pressure of 15 bara was used for the first-stage separator and the inlet static pressure (reservoir pressure) was input from the reservoir pressure obtained in the reservoir's material balance model. The production system model data (black-oil model and productivity index data, well and flowlines layout, etc.) are shown in "Appendix" (Tables 15, 16, 17, and 18).

Two types of production systems were modeled to account for the recovery strategies tested. For the recovery strategies with gas lift, one production system model was created with a constant gas lift injection rate of $3 \mathrm{MM} \mathrm{scf/d}$ in each well. For the strategies with multiphase boosting, a second production system was created with Framo HelicoAxial multiphase boosters located in the flowlines placed between the clusters and the riser base. A maximum power consumption of $3800 \mathrm{~kW}$ was input.

The results of the material balance model for the whole production horizon were then used as an input in the network model. A script was programmed in Excel to transfer the material balance results of a given time to the network model. The script uses an application programming interface called OpenLink (Schlumberger 2012b). The script then runs the network model, gets the flow rates and stores them in an Excel spreadsheet. The process is repeated for all time steps. Figure 3 shows a diagram of the process.

The coupling location between the material balance model and the network model was at the bottom-hole. The results transferred from MBAL to PIPESIM were reservoir pressure GOR and WC. The result of this coupling is a set of curves (proxy model) of maximum oil rate, producing GOR and WC as function of cumulative oil production and number of wells. These proxy models are shown in Figs. 14, 15 and 16 in "Appendix."

\section{Step 3: cost estimation}

A commercial software for the estimation of costs in offshore production systems was used (Acona 2018). Here, a sensitivity analysis took place, where CAPEX, OPEX and DRILLEX were estimated for different values of oil rate, gas rate and water rate capacities of the topside facility and

Fig. 3 Coupling process used

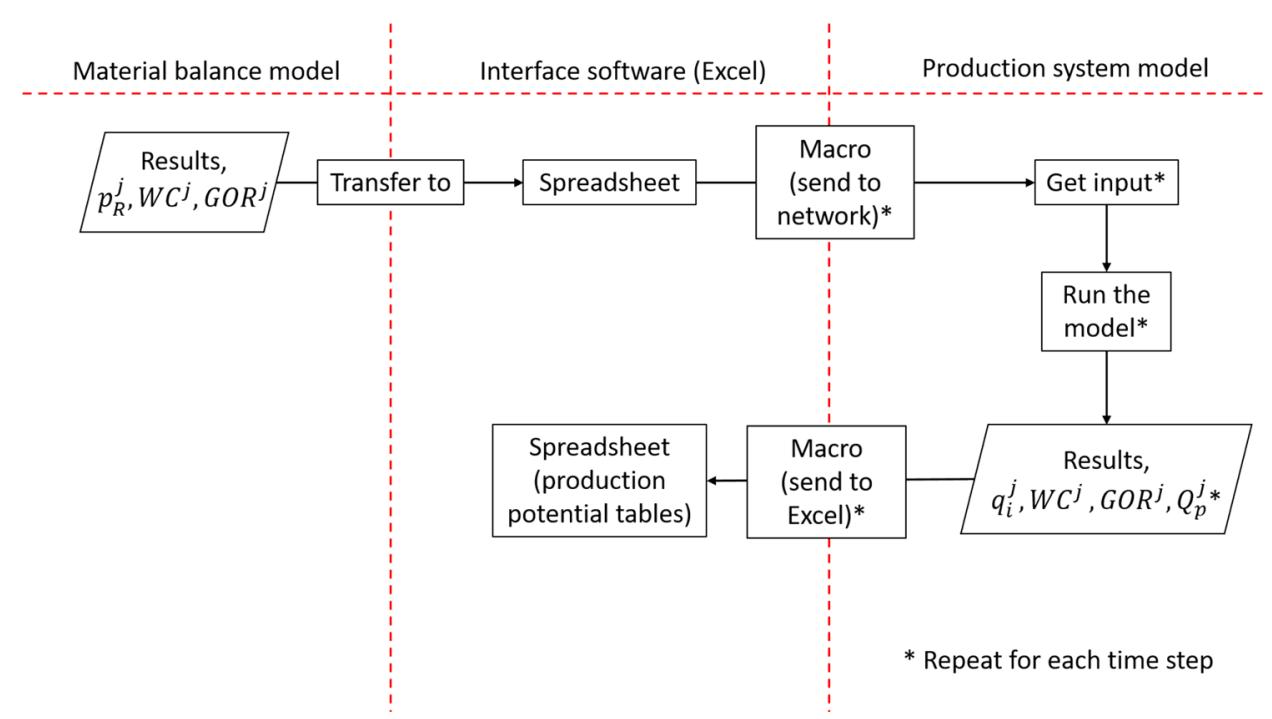

Table 1 Costs sensitivity analysis

\begin{tabular}{lllc}
\hline Oil rate $\mathrm{Sm}^{3} / \mathrm{d}(\mathrm{stb} / \mathrm{d})$ & $\begin{array}{l}\text { Gas rate } \mathrm{MM} \mathrm{Sm}^{3} / \mathrm{d} \\
(\mathrm{MM} \mathrm{scf} / \mathrm{d})\end{array}$ & Water rate $\mathrm{Sm}^{3} / \mathrm{d}(\mathrm{stb} / \mathrm{d})$ & $\begin{array}{l}\text { N. wells } \\
\text { (prod +inj) }\end{array}$ \\
\hline $5000(31,449)$ & $1.5(53)$ & $20,000(125,796)$ & $10+10$ \\
$15,000(94,347)$ & $2.5(88)$ & $30,000(188,694)$ & $15+15$ \\
$25,000(157,245)$ & $3.5(124)$ & $40,000(251,592)$ & $20+20$ \\
\hline
\end{tabular}


number of production and injection wells. Table 1 gives the values used for the sensitivity analysis.

For CAPEX and OPEX, the maximum number of production and injection wells that can be drilled in the field is used. Therefore, the drilling schedule found by the optimizer does not affect these costs, while DRILLEX is estimated using the amount of wells (production and injection) drilled in a specific period. For the evaluation of this methodology, all the capital expenses are assumed to take place from year zero to year three, operational costs are taken as yearly average values, and drilling costs are calculated yearly.

Having the cost data values, a multivariable linear regression with the CAPEX, OPEX and DRILLEX data was performed for the three topside facilities considered. The equations obtained are used as a proxy model to estimate the costs during the optimization. The costs proxy models are presented in Eqs. (69) to (75) in "Appendix," and the standard error and R-squared for these models are shown in Table 19.

\section{Step 4: optimization}

For each development concept, the production profile and drilling schedule that give maximum profit were estimated using optimization. For this, some assumptions were considered:

- Constant oil price: 500 NOK/stb (62.5 USD/stb).

- Discount rate $=8 \%$.

- All wells start production at the beginning of the year they are drilled.

- A table of cumulative water injected versus cumulative oil production was used to calculate the water injection rate. This is shown in Table 20 in "Appendix."

- The time steps have a duration of 1 year

- The following constraint was applied:

- The maximum number of production wells that can be drilled in a time step is 4 wells.

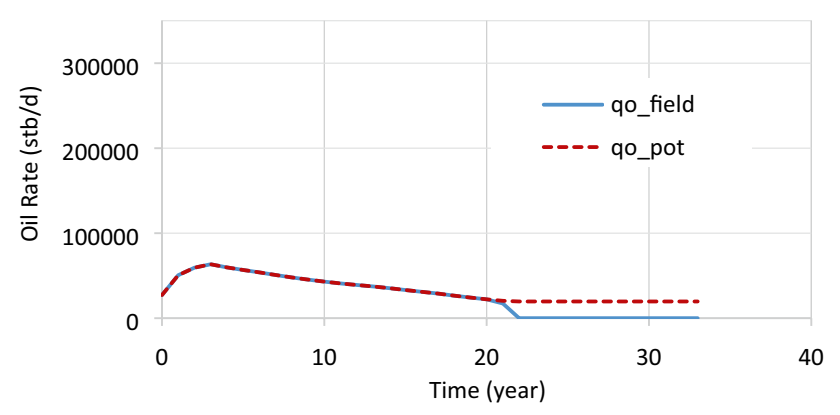

Fig. 4 Optimum oil production profile and oil production potential for strategy TLP with gas lifted wells
- The maximum number of production wells in field is 15 wells.

- The maximum oil rate per well allowed to avoid erosion in the production system is $13,000 \mathrm{stb} / \mathrm{d}$.

- The maximum water injection per well is $6290 \mathrm{stb} / \mathrm{d}$ (valid for the cases with water injection).

- During the optimization, only the optimal drilling schedule of the production wells is computed. Therefore, to estimate the costs, it is assumed that the field has the same amount of production and injection wells.

The simulations were run in a workstation with an Intel ${ }^{\circledR}$ Xeon ${ }^{\circledR} \mathrm{W}-2145$ processor and 64 GB of RAM. The running time of one optimization case ranged between $9 \mathrm{~s}$ and $8 \mathrm{~h}$. Figures 4, 5 and 6 show the optimum production profile obtained for three development strategies combined with TLP as topside facility. The results for all cases are presented in "Appendix" (Figs. 17, 18, 19, 20, 21, 22, 23, 24, and 25).

From the production profiles obtained, it was observed that the topside facilities do not have influence on the oil production rate. The type of topside facility affects the costs and, subsequently, the NPV. The NPV depends on both costs and production profile Therefore, the topside facility should, in theory, influence the production profile. However,

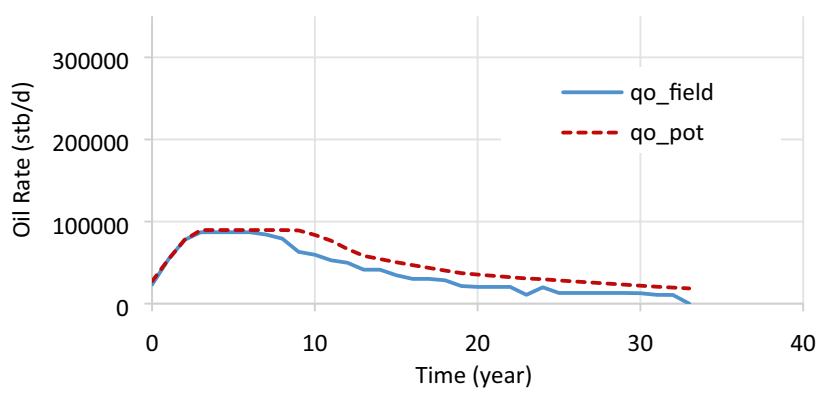

Fig. 5 Optimum oil production profile and oil production potential for strategy TLP with GL + WI

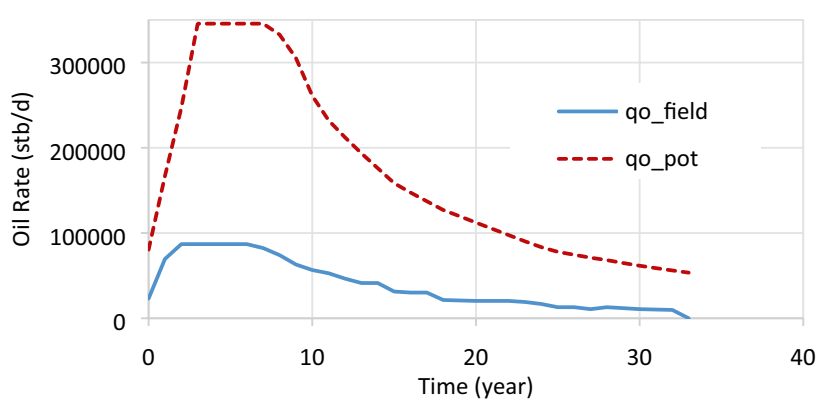

Fig. 6 Optimum oil production profile and oil production potential for strategy TLP with MPB + WI 
the results show that this influence is negligible for the cases studied.

Regarding the influence of the recovery methods over the oil production profile, the cases with gas lifted wells gave the lowest oil production. In addition, for these cases, the optimal production schedule consists of producing at the field potential rate.

The cases with gas lift + water injection and multiphase boosting + water injection gave similar production profiles. For these cases, it was obtained that the optimal production rate is lower than the production potential rate of the field. This happens because, even though, for these cases, the field has the capacity to produce at higher rates, a greater oil production would infringe one or more constraints in the optimization formulation. The influence of the oil production is reflected on the revenues, higher production gives higher revenues, and on the costs since a higher production means processing facilities with higher capacity are needed.

The drilling schedule for all the development strategies is shown in Table 2. It will be mostly influenced by the cost of drilling each well and the capacity of the strategy to produce revenues that overcome that cost. For this study case, the drilling schedule remains mostly the same regardless of the strategy used. The optimum schedule is to drill the maximum number of wells allowed in each time step until the total number of wells that can be drilled in the field is reached. The combinations of Tie-back and FPSO, the costliest platforms, with GL, the scenario with less oil production, are the only strategies that give a lower number of wells drilled.

Table 3 shows the NPV obtained for each strategy. These results are shown at an abandonment rate of 20,000 stb/d. This rate was chosen because, for some strategies, the cash flow becomes negative when the oil rate drops at approximately $20,000 \mathrm{stb} / \mathrm{d}$, negative cash flow means that the revenues are lower than the expenses.

Based on Table 3, it can be concluded that the best development strategy to exploit this synthetic field would be to use a TLP platform in combination with MPB + WI. This
Table 3 Maximum NPV obtained for each development strategy

\begin{tabular}{llll}
\hline NPV (billion NOK) & & & \\
\hline & TLP & FPSO & Tie-back \\
\hline GL & 45.29 & 39.94 & 36.88 \\
GL + WI & 71.19 & 64.98 & 60.02 \\
MPB + WI & 74.71 & 69.67 & 63.01 \\
\hline
\end{tabular}

conclusion is done using a deterministic calculation, i.e., assuming that there is no uncertainty in the input. However, in reality, there are many uncertainties related with the reservoir volumes and properties, fluid characteristics, costs, etc. To perform a proper field development study, an analysis and quantification of uncertainties are necessary. This is performed in the step 5 .

\section{Sept 5: uncertainty}

The effect of uncertainty was evaluated using discrete cases with probability trees. Uncertainties in the production potential curves (proxy models) and the costs were considered.

For the potential curves, uncertainties on the size of the reservoir (initial oil in place), the layout of the production system (Fig. 7) and the Joshi's steady-state productivity index (PI) were used. The steady-state productivity model of Joshi involves several reservoir parameters to calculate the productivity index of a well. However, to simplify the process, the uncertainty in PI was accounted only with uncertainty in the horizontal and vertical permeability $\left(K_{\mathrm{h}}\right.$ and $K_{\mathrm{v}}$ ).

Seven production potential curves were generated for each recovery strategy. This resulted in 21 uncertainty cases (the type of topside facility has a negligible influence on the production potential curve). Figure 8 presents a decision tree diagram showing these cases and their corresponding probability.

Since the methodology was tested in a synthetic reservoir based on public data of Wisting field, there is no information
Table 2 Optimum drilling schedule for all strategies

\begin{tabular}{llllllll}
\hline Year & \multicolumn{9}{l}{ Number of wells drilled per year } & & Total Nw \\
\cline { 2 - 7 } & 1 & 2 & 3 & 4 & 5 & $\ldots$ & \\
\hline TLP+GL & 4 & 4 & 4 & 3 & 0 & 0 & 15 \\
FPSO +GL & 4 & 4 & 4 & 2 & 0 & 0 & 14 \\
Tie-back + GL & 4 & 4 & 4 & 2 & 0 & 0 & 14 \\
TLP+GL+ WI & 4 & 4 & 4 & 3 & 0 & 0 & 15 \\
FPSO +GL+ WI & 4 & 4 & 4 & 3 & 0 & 0 & 15 \\
Tie-back + GL + WI & 4 & 4 & 4 & 3 & 0 & 0 & 15 \\
TLP+ MPB + WI & 4 & 4 & 4 & 3 & 0 & 0 & 15 \\
FPSO+MPB + WI & 4 & 4 & 4 & 3 & 0 & 0 & 15 \\
Tie-back + MPB + WI & 4 & 4 & 4 & 3 & 0 & 0 & 15 \\
\hline
\end{tabular}


Fig. 7 Uncertainty in production system layout

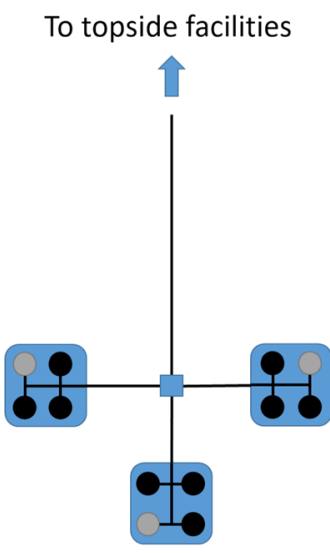

Production system layout with clustered wells
To topside facilities

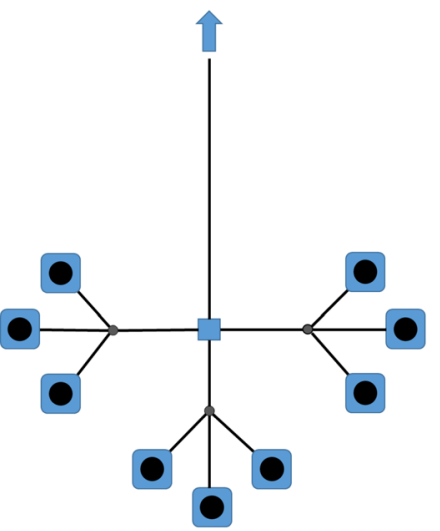

Production system layout with satellite wells
To topside facilities

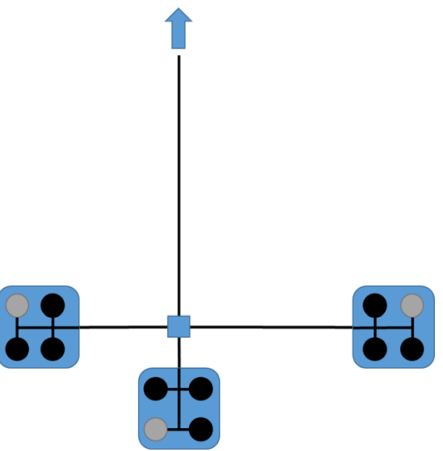

Asymmetric Production system layout
Fig. 8 Decision tree diagram for potential curves uncertainty

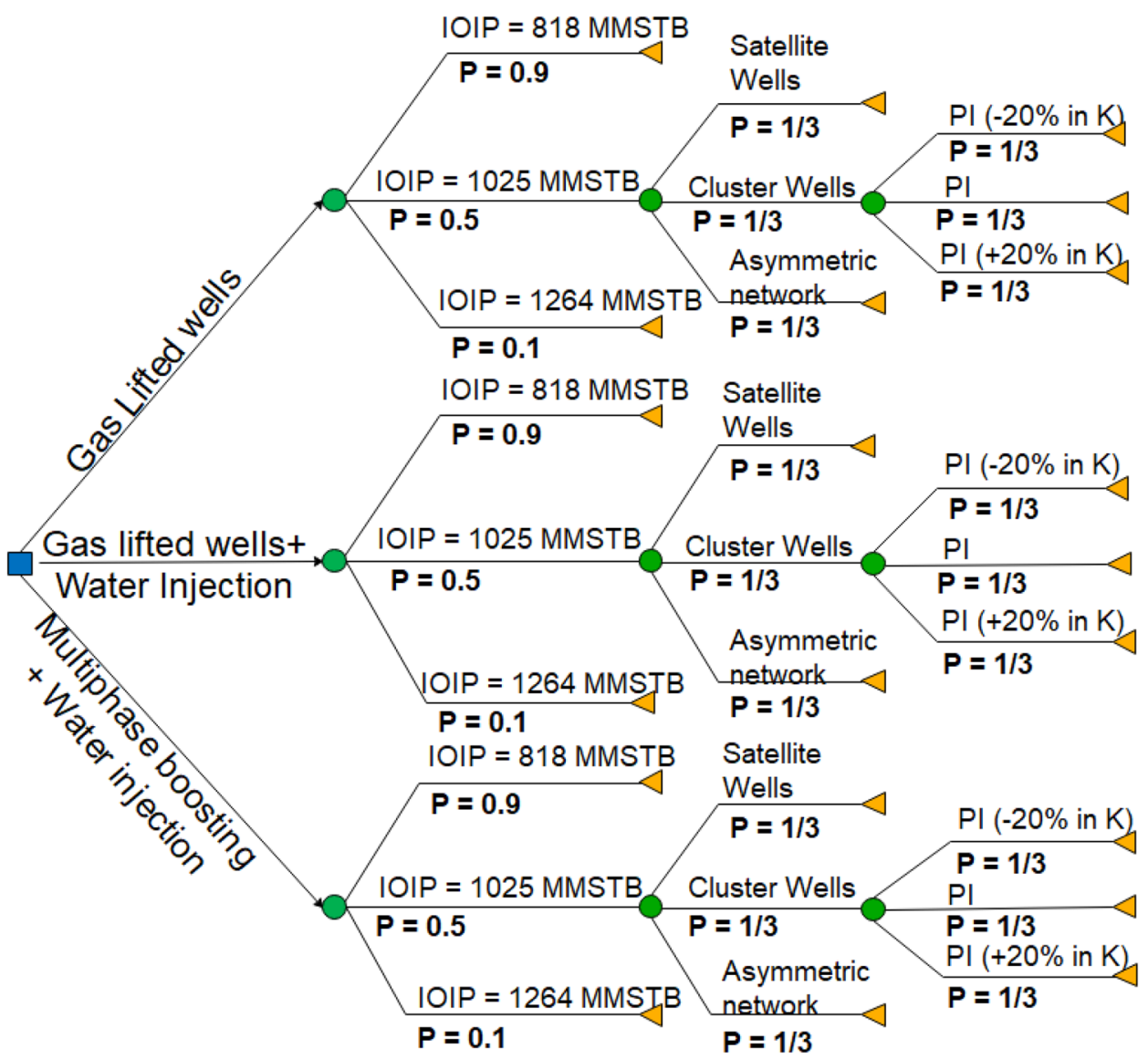

available about the layout configuration of the subsea system or the productivity index. Therefore, the uncertainty values used for these two parameters were assumed to have equal probability. This means that each one of the three cases of production system layout has a probability of $1 / 3$, and the same applies for the cases of productivity index (each has a probability of 1/3). In the cases of the reservoir size, the uncertainty used corresponds to information available in public domain, so does the probabilities.

The costs values obtained from the cost proxy models were varied in $\pm 20 \%$ to account for uncertainty in these variables. This results in three uncertainty cases in which CAPEX, OPEX and DRILLEX were varied simultaneously. They are shown in Fig. 9. 


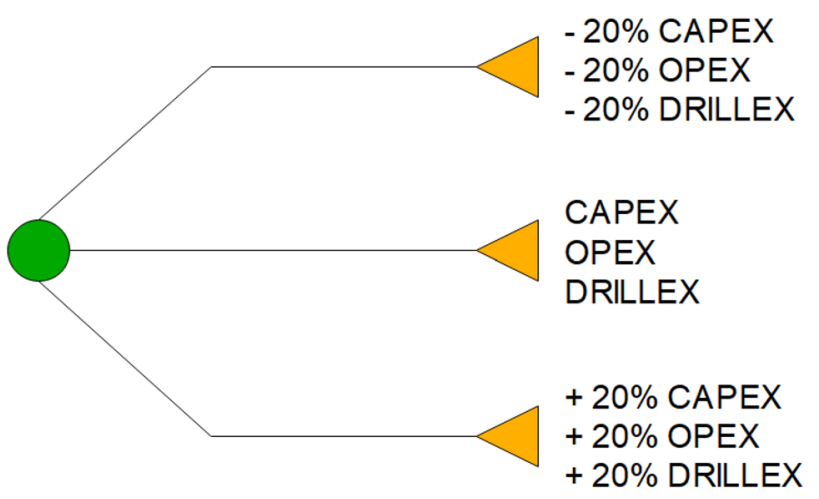

Fig. 9 Decision tree diagram for costs uncertainty

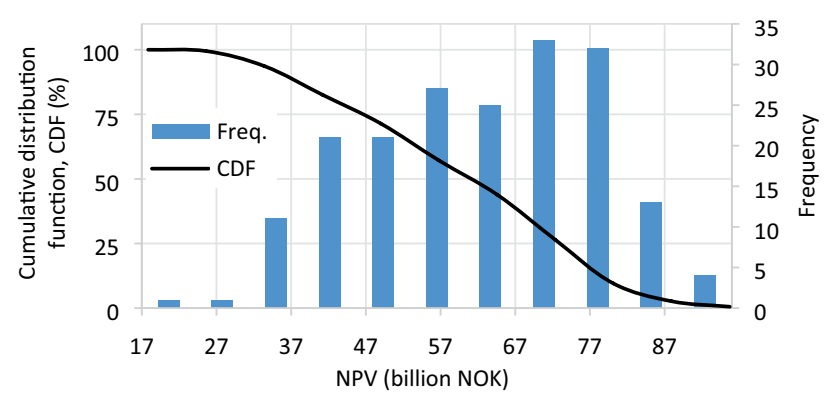

Fig. 10 NPV's cumulative density function. All uncertainty cases

Table 4 NPV's probabilities

\begin{tabular}{llll}
\hline \multicolumn{4}{l}{ NPV (billion NOK) } \\
\hline & P10 & P50 & P90 \\
\hline All cases & 35.98 & 60.99 & 79.93 \\
\hline
\end{tabular}

The cost uncertainty was applied to the 21 curves of production potential, resulting in 63 uncertainty cases. Additionally, the 63 cases were repeated for each topside facility, giving 189 simulations for the uncertainty analysis. Step 4 was applied for each one of these cases.

The software Pipe-It was used to setup the uncertainty analysis. This software allows running the optimization while varying the inputs of production potential curves and costs. This is done automatically, and Pipe-It is configured to select each production potential proxy model and vary the cost in the established range. Then, it executes the AMPL file to run the optimization. Finally, the results of each optimization run are stored by Pipe-It.

Figure 10 shows the NPV's cumulative distribution function obtained in the uncertainty analysis. From this, it is possible to identify the probability that the NPV takes a value between a specific range. In the case of this analysis, the NPV can range between 17.85 and 95.72 billion NOK. The P10, P50 and P90 values are shown in Table 4.

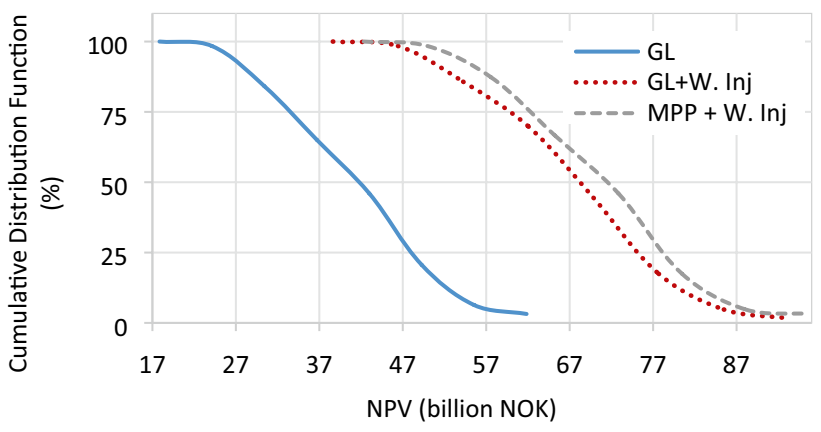

Fig. 11 Comparison of NPV's cumulative density function for all recovery scenarios

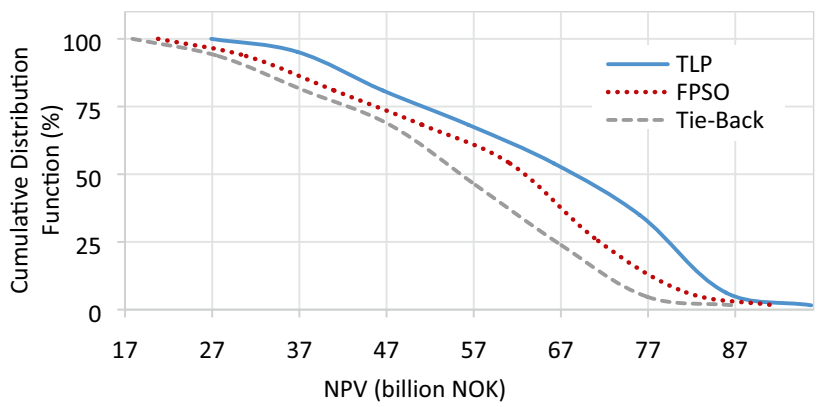

Fig. 12 Comparison of NPV's cumulative density function for all topside facilities

Figures 11 and 12 compare the influence of each recovery scenario and each topside facility over the NPV, respectively. Figure 11 shows that the recovery scenario that gives the highest values of NPV is MPB + WI, followed closely by $\mathrm{GL}+\mathrm{WI}$; the less profitable scenario is GL. These results are influenced by the amount of production that can be obtained from each scenario.

The topside facilities influence the NPV through the costs. Figure 12 shows that the most profitable facility is TLP, since it has the lower costs. The next is the FPSO and finally the Tie-back to existing facilities. Tie-back to existing facilities does not account costs of platform. However, the costs of the pipeline and umbilical system are higher in comparison with TLP and FPSO due to the larger distance they need to cover $(150 \mathrm{~km})$.

The results from Figs. 11 and 12 are in accordance with what was obtained before in the step 4 (Table 3). The P10, P50 and P90 values for the three recovery scenarios concepts and the three topside facilities concepts are shown in Table 5. 
Table 5 NPV probabilities

NPV (billion NOK)

\begin{tabular}{llll}
\hline & P10 & P50 & P90 \\
\hline GL & 27.83 & 41.68 & 53.95 \\
GL+W. Inj & 51.61 & 68.15 & 82.26 \\
MPB + W. Inj & 55.73 & 71.37 & 84.95 \\
TLP & 40.33 & 68.27 & 84.63 \\
FPSO & 33.79 & 62.58 & 79.44 \\
Tie-back & 30.52 & 55.45 & 74.18 \\
\hline
\end{tabular}

Recovery scenarios and topside facilities

\section{Conclusions}

An automated methodology that uses integrated asset modeling, mathematical optimization and analysis of uncertainties to perform field design in early stages of the field development process, was developed. The methodology employs proxy models of the production performance of the field and the costs that reduce complexity and computational simulation time. The proxy models of the production performance are based on the concept of production potential used in reservoir engineering, and the costs models consist of linear equation obtained from standard regression analysis of cost data. Mathematical optimization is used to determine the best production profile and well drilling schedule that maximize economic profit for a specific field development strategy. The effect of uncertainty and several design alternatives is quantified using probability trees.

The methodology was evaluated in a synthetic field where the profitability of nine development strategies was compared. The development strategies were obtained from the combination of three recovery scenarios (GL, GL + WI and $\mathrm{MPB}+\mathrm{WI}$ ) and three topside facilities (TLP, FPSO and Tieback). As a result, the best strategy was determined using the NPV as main decision factor, and other factors were the oil production and drilling schedule. The best strategy was TLP with MPB + WI. This strategy generated the highest production and required the lowest costs, resulting in the highest profitability.

The effect of uncertainty was evaluated using discrete cases with probability trees (a total of 189 cases). Uncertainties in the reservoir, the production system layout, productivity index and cost were considered. From this analysis, it was determined that the NPV has probable values that range from 18 to 96 billion NOK.

The methodology provides decision support when performing field planning and demonstrated to successfully find optimal field design features in an automated manner while quantifying the effect of uncertainties.
Table 6 Set of time steps

\begin{tabular}{ll}
\hline Set & Description \\
\hline$T$ & Set of all time steps
\end{tabular}

Table 7 Optimization parameters

\begin{tabular}{ll}
\hline Parameter & Description \\
\hline$q_{o, \text { erosion }}^{\max }$ & Maximum oil rate allow to avoid erosion (stb/d) \\
$q_{w, \text { inj }}^{\max }$ & Maximum water injection (stb/d) \\
$\mathrm{Nw}_{\text {drilled }}^{\min }$ & $\begin{array}{c}\text { Minimum number of well that can be drilled in a time } \\
\text { step }\end{array}$ \\
$\mathrm{Nw}_{\text {drilled }}^{\max }$ & Maximum number of wells that can be drilled in a time \\
$P_{o}$ & step \\
$\mathrm{DR}$ & Oil price (NOK/stb) \\
$\Delta t$ & Discount rate (\%) \\
\hline
\end{tabular}

Table 8 Field variables

\begin{tabular}{ll}
\hline Variable & Description \\
\hline$q_{o}^{j}$ & Oil production rate for time step $j$ (stb/d) \\
$q_{o, \text { pot }}^{j}$ & Oil production potential rate for time step $j(\mathrm{stb} / \mathrm{d})$ \\
$q_{g}^{j}$ & Gas production rate for time step $j(\mathrm{MM} \mathrm{scf} / \mathrm{d})$ \\
$q_{w}^{j}$ & Water production rate for time step $j(\mathrm{stb} / \mathrm{d})$ \\
$q_{w, \text { inj }}^{j}$ & Water injection rate for time step $j$ (stb/d) \\
$\mathrm{Np}^{j}$ & Cumulative oil production for time step $j$ (stb) \\
$\mathrm{Wp}_{\text {inj }}^{j}$ & Cumulative water injection for time step $j$ (stb) \\
$\mathrm{Nw}^{j}$ & Number of production wells in the field for time step $j$ \\
$\mathrm{Nw}_{\text {drilled }}^{j}$ & Number of well drilled for time step $j$ \\
$\mathrm{Nw}_{d, p+i}^{j}$ & Number of production and injection wells drilled for time \\
$\mathrm{Nw}^{\text {field }}$ & step $j$ \\
$\mathrm{GOR}^{j}$ & Maximum number of production and injection wells in the \\
$\mathrm{WC}^{j}$ & Gas oil rate for time step $j$ (scf/stb) \\
$q_{o}^{\text {capacity }}$ & Oater cut for time step $j$ (fraction) \\
$q_{g}^{\text {capacity }}$ & Gas rate capacity of processing facility (MM scf/d) \\
$q_{w}^{\text {capacity }}$ & Water rate capacity of processing facility (stb/d) \\
\hline &
\end{tabular}

Acknowledgements Authors acknowledge the financial support of this research by SUBPRO SFI and its industry partners.

Open Access This article is licensed under a Creative Commons Attribution 4.0 International License, which permits use, sharing, adaptation, distribution and reproduction in any medium or format, as long as you give appropriate credit to the original author(s) and the source, provide a link to the Creative Commons licence, and indicate if changes were made. The images or other third party material in this article are included in the article's Creative Commons licence, unless indicated 
otherwise in a credit line to the material. If material is not included in the article's Creative Commons licence and your intended use is not permitted by statutory regulation or exceeds the permitted use, you will need to obtain permission directly from the copyright holder. To view a copy of this licence, visit http://creativecommons.org/licenses/by/4.0/.

Table 9 Economic variables

\begin{tabular}{ll}
\hline Variable & Description \\
\hline$E_{\text {cap }}$ & Capital expenditures (MM NOK) \\
$E_{\mathrm{op}}$ & Operational expenditures (MM NOK) \\
$E_{\text {drill }}^{j}$ & Drilling expenditures for time step $j$ (MM NOK) \\
$\mathrm{CF}^{j}$ & Cash flow for time step $j$ (MM NOK) \\
$\mathrm{NPV}^{j}$ & Net present value for time step $j$ (MM NOK) \\
\hline
\end{tabular}

Table 10 Set of breakpoints used in the MILP formulation

\begin{tabular}{ll}
\hline Set & Description \\
\hline$V_{\mathrm{Np}}^{j}$ & Set of cumulative oil production breakpoints for time step $j$ \\
$N_{\mathrm{Nw}}^{j}$ & Set of number of wells breakpoints for time step $j$ \\
$Q_{q o}^{j}$ & Set of oil rate breakpoints for time step $j$ \\
$R_{\mathrm{gor}}^{j}$ & Set of GOR breakpoint for time step $j$ \\
$R_{\mathrm{wc}}^{j}$ & Set of WC breakpoint for time step $j$ \\
\hline
\end{tabular}

Table 11 Auxiliary variables used in the MILP formulation

\begin{tabular}{ll}
\hline Variable & Description \\
\hline$\theta_{v . N}^{j}$ & Weighting variable for breakpoint $(\nu, N)$, time step $j$ \\
$\alpha_{v}^{j}$ & SOS2 variable for breakpoint $v$, time step $j$ \\
$\beta_{N}^{j}$ & SOS2 variable for breakpoint $N$, time step $j$ \\
$\theta_{q, r_{\mathrm{gor}}}^{j}$ & Weighting variable for breakpoint $\left(q, r_{\mathrm{gor}}\right)$, time step $j$ \\
$\alpha_{q}^{j}$ & SOS2 variable for breakpoint $q$, time step $j$ \\
$\beta_{r_{\mathrm{gor}}}^{j}$ & SOS2 variable for breakpoint $r_{\mathrm{gor}}$, time step $j$ \\
$\theta_{q, r_{\mathrm{wc}}}^{j}$ & Weighting variable for breakpoint $\left(q, r_{\mathrm{wc}}\right)$, time step $j$ \\
$\beta_{r_{\mathrm{wc}}}^{j}$ & SOS2 variable for breakpoint $r_{\mathrm{wc}}$, time step $j$ \\
$\lambda_{v}^{j}$ & Weighting variable for breakpoint $v$, time step $j$ \\
\hline
\end{tabular}

\section{Appendix: Mixed-integer linear formulation of the optimization problem}

Here, the formulation used to solve the optimization problem is presented.

See Tables 6, 7, 8, 9, 10, 11 and 12 .

$$
\forall j \in T \text { : }
$$

$\max _{\gamma} \mathrm{NPV}$

with $\gamma$ the set of variables defined in Tables 9, 10 and 12 . The problem is subjected to the following constraints:

$\mathrm{NPV}=\sum_{j \in T} \mathrm{CF}^{j}$

$\forall j \in T:$

$\mathrm{CF}^{j}=\frac{\left(\mathrm{Np}^{j} \cdot P_{o}^{j}\right)-\left(E_{\mathrm{cap}}^{j}+E_{\mathrm{op}}^{j}+E_{\mathrm{drill}}^{j}\right)}{(1+\mathrm{DR})^{j}}$

$E_{\text {cap }}^{j}, E_{\mathrm{op}}^{j}$ and $E_{\text {drill }}^{j}$ are estimated from Eqs. (12) to (14). The cumulative oil produced, number of wells in the field and water injection rate are given by

$\mathrm{Np}^{i}=\sum_{j \in T} \Delta t \cdot q_{o}^{j-1}$

$\mathrm{Nw}^{i}=\sum_{j \in T} \mathrm{Nw}_{\mathrm{drilled}}^{j}$

$q_{w, \text { inj }}^{j}=\frac{\mathrm{Wp}_{\mathrm{inj}}^{j}-\mathrm{Wp}_{\mathrm{inj}}^{j-1}}{\Delta t}$

The optimization is subject to the operational constraints described in "Study case" section:

$q_{o}^{j} \leq q_{o, \text { pot }}^{j}$

$\mathrm{Nw}_{\text {drilled }}^{\text {min }} \leq \mathrm{Nw}_{\text {drilled }}^{j} \leq \mathrm{Nw}_{\text {drilled }}^{\text {max }}$
Table 12 Piecewise linear functions used in MILP

\begin{tabular}{|c|c|}
\hline Function & Description \\
\hline$\widehat{q_{o, \text { pot }}^{j}}$ & $\begin{array}{l}\text { PWL function given the oil production potential as function of cumulative oil produced } \\
\text { and number of wells }\end{array}$ \\
\hline$\widehat{\mathrm{GOR}^{j}}$ & PWL function given the GOR as function of cumulative oil produced and number of wells \\
\hline$\widehat{\mathrm{WC}}^{j}$ & PWL function given the WC as function of cumulative oil production and number of wells \\
\hline$\widehat{q_{g}^{j}}$ & PWL function given the gas rate as function of oil rate and GOR \\
\hline$\widehat{q_{w}^{j}}$ & PWL function given the water rate as function of oil rate and WC \\
\hline$\widehat{\mathrm{Wp}_{\mathrm{inj}}^{j}}$ & PWL function given the cumulative water injected as function of cumulative oil produced \\
\hline
\end{tabular}


$q_{o, \text { pot }}=q_{o, \text { pot }}(\mathrm{Np}, \mathrm{Nw})$

$q_{o}^{j} \leq q_{o, \text { erosion }}^{\max }$

$q_{w, \text { inj }}^{j} \leq q_{w, \text { inj }}^{\max }$

$q_{o}^{\text {capacity }} \geq q_{o}^{j}$

$q_{g}^{\text {capacity }} \geq q_{g}^{j}$

$q_{w}^{\text {capacity }} \geq q_{w}^{j}$

$\mathrm{Nw}^{\text {field }} \geq \mathrm{Nw}^{j}$

The oil production potential, GOR and WC are given by

$q_{o, \mathrm{pot}}^{j}=\sum_{\nu \in V_{\mathrm{Np}}^{j}} \sum_{N \in N_{\mathrm{Nw}}^{j}} \theta_{\nu N}^{j} \cdot \widehat{q_{o, \mathrm{pot}}^{j}}(\nu, N)$

$\mathrm{GOR}^{j}=\sum_{v \in V_{\mathrm{Np}}^{j}} \sum_{N \in N_{\mathrm{Nw}}^{j}} \theta_{v N}^{j} \cdot \widehat{\mathrm{GOR}^{j}}(\nu, N)$

$\mathrm{WC}^{j}=\sum_{\nu \in V_{\mathrm{Np}}^{j}} \sum_{N \in N_{\mathrm{Nw}}^{j}} \theta_{v N}^{j} \cdot \widehat{\mathrm{WC}}^{j}(\nu, N)$

$\mathrm{Np}^{j}=\sum_{v \in V_{\mathrm{Np}}^{j}} \sum_{N \in N_{\mathrm{Nw}}^{j}} \theta_{v N}^{j} \cdot v$

$\mathrm{Nw}^{j}=\sum_{\nu \in V_{\mathrm{Np}}^{j}} \sum_{N \in N_{\mathrm{Nw}}^{j}} \theta_{\nu N}^{j} \cdot N$

$$
\sum_{v \in V_{\mathrm{Np}}^{j}} \sum_{N \in N_{\mathrm{Nw}}^{j}} \theta_{v N}^{j}=1
$$

$\forall v \in V_{\mathrm{Np}}^{j}, \quad \forall N \in N_{\mathrm{Nw}}^{j}, \quad \theta_{\nu N}^{j} \geq 0$

$\forall v \in V_{\mathrm{Np}}^{j}, \quad \alpha_{v}^{j}=\sum_{N \in N_{\mathrm{Nw}}^{j}} \theta_{v N}^{j}$

$\forall N \in N_{\mathrm{Nw}}^{j}, \quad \beta_{N}^{j}=\sum_{v \in V_{\mathrm{Np}}^{j}} \theta_{v N}^{j}$

$\left(\alpha_{v}^{j}\right)_{v \in V_{\mathrm{Np}}^{j}}$ is a SOS2
$\left(\beta_{N}^{j}\right)_{N \in N_{\mathrm{NW}}^{j}}$ is a SOS2

As mentioned, Eqs. (19) and (20), being bilinear, require some additional manipulation to be included in the MILP. The gas rate is given by

$q_{g}^{j}=\sum_{q \in Q_{q o}^{j}} \sum_{r_{\text {gor }} \in R_{\text {gor }}^{j}} \theta_{q r_{\text {gor }}}^{j} \cdot \widehat{q}_{g}^{j}\left(q, r_{\text {gor }}\right)$

$q_{o}^{j}=\sum_{q \in Q_{q o}^{j}} \sum_{r_{\mathrm{gor}} \in R_{\mathrm{gor}}^{j}} \theta_{q r_{\mathrm{gor}}}^{j} \cdot q$

$\mathrm{GOR}^{j}=\sum_{q \in Q_{q o}^{j}} \sum_{r_{\mathrm{gor}} \in R_{\mathrm{gor}}^{j}} \theta_{q r_{\mathrm{gor}}}^{j} \cdot r_{\mathrm{gor}}$

$\sum_{q \in Q_{q o}^{j}} \sum_{r_{\mathrm{gor}} \in R_{\mathrm{gor}}^{j}} \theta_{q r_{\mathrm{gor}}}^{j}=1$

$\forall q \in Q_{q o}^{j}, \quad \forall r_{\text {gor }} \in R_{\text {gor }}^{j}, \quad \theta_{q r_{\text {gor }}}^{j} \geq 0$

$\forall q \in Q_{q o}^{j}, \quad \alpha_{q}^{j}=\sum_{r_{\mathrm{gor}} \in R_{\mathrm{gor}}^{j}} \theta_{q r_{\mathrm{gor}}}^{j}$

$\forall r_{\text {gor }} \in R_{\text {gor }}^{j}, \quad \beta_{r_{\mathrm{gor}}}^{j}=\sum_{q \in Q_{q o}^{j}} \theta_{q r_{\mathrm{gor}}}^{j}$

$\left(\alpha_{q}^{j}\right)_{q \in Q_{q o}^{j}}$ is a SOS2

$\left(\beta_{r_{\mathrm{wc}}}^{j}\right)_{r_{\mathrm{gor}} \in R_{\mathrm{gor}}^{j}}$ is a SOS2

The water rate is given by

$$
\begin{aligned}
& q_{w}^{j}=\sum_{q \in Q_{q o}^{j}} \sum_{r_{\mathrm{wc}} \in R_{\mathrm{wc}}^{j}} \theta_{q r_{\mathrm{wc}}^{j}} \cdot \widehat{q}_{w}^{j}\left(q, r_{\mathrm{wc}}\right) \\
& q_{o}^{j}=\sum_{q \in Q_{q o}^{j}} \sum_{r_{\mathrm{wc}} \in R_{\mathrm{wc}}^{j}} \theta_{q r_{\mathrm{wc}}}^{j} \cdot q \\
& \mathrm{WC}^{j}=\sum_{q \in Q_{q o}^{j}} \sum_{r_{\mathrm{wc}} \in R_{\mathrm{wc}}^{j}} \theta_{q r_{\mathrm{wc}}}^{j} \cdot r_{\mathrm{wc}} \\
& \sum_{q \in Q_{q o}^{j}} \sum_{r_{\mathrm{wc}} \in R_{\mathrm{wc}}^{j}} \theta_{q r_{\mathrm{wc}}}^{j}=1
\end{aligned}
$$

$\forall q \in Q_{q o}^{j}, \quad \forall r_{\mathrm{wc}} \in R_{\mathrm{wc}}^{j}, \quad \theta_{q r_{\mathrm{wc}}}^{j} \geq 0$

$\forall q \in Q_{q o}^{j}, \quad \alpha_{q}^{j}=\sum_{r_{\mathrm{wc}} \in R_{\mathrm{wc}}^{j}} \theta_{q r_{\mathrm{wc}}}^{j}$ 
$\forall r_{\mathrm{wc}} \in R_{\mathrm{wc}}^{j}, \quad \beta_{r_{\mathrm{wc}}}^{j}=\sum_{q \in Q_{q o}^{j}} \theta_{q r_{\mathrm{wc}}}^{j}$

$\left(\alpha_{q}^{j}\right)_{q \in Q_{q o}^{j}}$ is a SOS2

$\left(\beta_{r_{\mathrm{wc}}}^{j}\right)_{r_{\mathrm{wc}} \in R_{\mathrm{wc}}^{j}}$ is a SOS2

The cumulative water injection is given by

$$
\begin{aligned}
& \mathrm{Wp}_{\mathrm{inj}}^{j}=\sum_{v \in V_{\mathrm{Np}}^{j}} \lambda_{v}^{j} \cdot \widehat{\mathrm{Wp}_{\mathrm{inj}}^{j}}(v) \\
& \mathrm{Np}^{j}=\sum_{\nu \in V_{\mathrm{Np}}^{j}} \lambda_{v}^{j} \cdot v
\end{aligned}
$$

$\sum_{v \in V_{\mathrm{Np}}^{j}} \lambda_{v}^{j}=1$

$\forall v \in V_{\mathrm{Np}}^{j}, \quad \lambda_{v}^{j} \geq 0$

\section{Average properties of Wisting field}

See Table 13.
Table 13 Field properties used for the study case

\begin{tabular}{ll}
\hline Property & Value \\
\hline Reservoir temperature $\left({ }^{\circ} \mathrm{C}\right)$ & 17.7 \\
Reservoir pressure (bara) & 71.4 \\
Bubble point pressure (bara) & 64.4 \\
Two stage GOR (Sm3/Sm3) & 44.6 \\
Bo @ Pb (m3/Sm3) & 1.076 \\
Oil API & 39 \\
Base IOIP (MMstb) & 1025 \\
\hline
\end{tabular}

\section{Input data for material balance model}

See Table 14 and Fig. 13.

\begin{tabular}{|c|c|c|c|}
\hline \multicolumn{2}{|l|}{ Tank parameter } & \multicolumn{2}{|l|}{ Water influx } \\
\hline Tank type & Oil & Model & $\begin{array}{l}\text { Hurst-van } \\
\text { Everdingen- } \\
\text { modified }\end{array}$ \\
\hline Temperature $\left({ }^{\circ} \mathrm{C}\right)$ & 17.7 & System & Linear aquifer \\
\hline Initial pressure (bara) & 71.4 & Boundary & Infinite acting \\
\hline Porosity (\%) & 25.0 & Reservoir thickness (m) & 125 \\
\hline Connate water saturation (fraction) & 0.1 & Reservoir width (m) & 2200 \\
\hline Water compressibility (1/psi) & Use Corr & Aquifer permeability (mD) & 400 \\
\hline Gas cap (downhole ratio) & 0.0 & & \\
\hline Original oil in place (MMstb) & 1025.0 & & \\
\hline Black-oil model & & Tank prediction data & \\
\hline Formation GOR (Sm3/Sm3) & 44.6 & Avg. oil rate (stb/d) & 110000.0 \\
\hline Oil gravity (API) & 39.0 & Water void replac. $(\%)$ & 100.0 \\
\hline Gas gravity (sp. gravity) & 0.8795 & Avg. water inj rat (stb/d) & 6290.0 \\
\hline $\mathrm{Pb}, \mathrm{Rs}$, Bo correlation & Standing & Water sat. breakthrough (fraction) & 0.3 \\
\hline Oil viscosity correlation & Beggs et al. & Gas sat. breakthrough (fraction) & 0.0 \\
\hline
\end{tabular}

Table 14 Reservoir model data 
Oil to Gas relative permeability

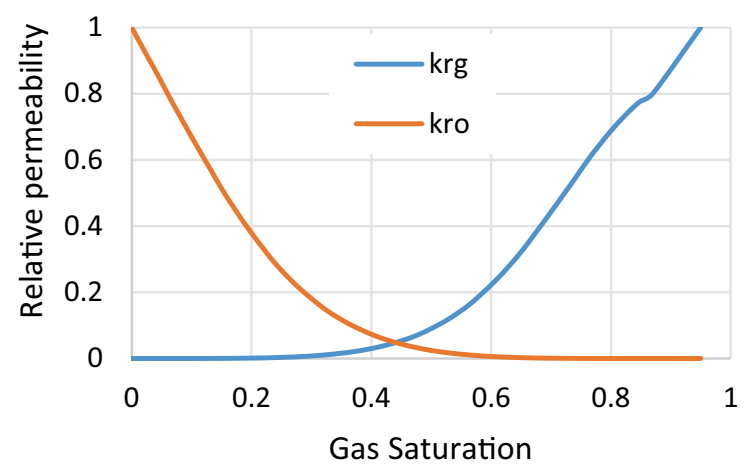

Oil to Water relative permeability

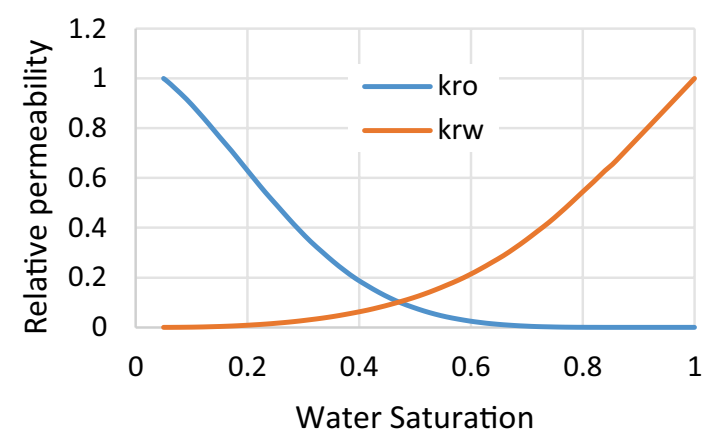

Fig. 13 Relative permeability curves used in material balance model

\section{Input data for network model}

See Tables 15, 16, 17 and 18.

Table 15 Black-oil and IPR model data used in network model

\begin{tabular}{llll}
\hline Black-oil model data & & \multicolumn{2}{l}{ IPR model data } \\
\hline WC (fraction) & Input from res. model & Distributed Pi (infinity conductivity) \\
GOR (Sm3/Sm3) & Input from res. model & Model type & SS oil (Joshi) \\
Gas S.G. & 0.8795 & Rextn (m) & 621.65 \\
API & 39 & Thickness (m) & 125.00 \\
Dead oil viscosity corr. & Beggs and Robinson & Kx (mD) & 1200.00 \\
Live oil viscosity corr. & Beggs and Robinson & Ky (mD) & 1200.00 \\
Rs, Bo corr. & Standing & Kz (mD) & 600.00 \\
& & Eccent (m) & 0.00 \\
& & Rw (in) & 9.63 \\
& & Skin & 0.00 \\
\hline
\end{tabular}

Table 16 Pipeline details

\begin{tabular}{|c|c|c|c|c|}
\hline & Well—manifold & Manifold—riser base & Riser base—sea level & Sea level一sink \\
\hline Inner diameter (in) & 4.8900 & 7.8130 & 10.02008 & 10.02 \\
\hline Wall thickness (in) & 0.3370 & 0.4320 & 0.365 & 0.37 \\
\hline Roughness (in) & 0.0018 & 0.0018 & 0.0018 & 0.0018 \\
\hline Total length (m) & 20 & 10000 & 450 & 30.00 \\
\hline Elevation inlet (m) & -450 & -450 & -450 & 0.00 \\
\hline Elevation outlet (m) & -450 & -450 & 0 & 30.00 \\
\hline Ambient temp inlet $\left({ }^{\circ} \mathrm{C}\right)$ & 4 & 4 & 4 & 0.00 \\
\hline Ambient temp outlet $\left({ }^{\circ} \mathrm{C}\right)$ & 4 & 4 & 0 & 0.00 \\
\hline$U$ value & Calculate & Calculate & Calculate & Calculate \\
\hline Pipe coating $K(\mathrm{Btu} / \mathrm{hr} / \mathrm{ft} / \mathrm{F})$ & 0.1156 & 0.1156 & 0.1156 & 0.1156 \\
\hline Pipe coating thickness (in) & 0.9843 & 0.9843 & 0.9843 & 0.9842 \\
\hline Pipe conductivity $(\mathrm{Btu} / \mathrm{hr} / \mathrm{fr} / \mathrm{F})$ & 31.7919 & 31.7919 & 31.7919 & 31.7919 \\
\hline Ambient fluid & Water & Water & Water & Air \\
\hline Ambient fluid vel. (ft/s) & 0.5741 & 0.5741 & 1.3095 & 16.4042 \\
\hline Pipe burial (in) & 0.0000 & 0.0000 & & \\
\hline $\begin{array}{l}\text { Ground conductivity half buried (Btu/ } \\
\mathrm{hr} / \mathrm{ft} / \mathrm{F} \text { ) }\end{array}$ & 0.8092 & 0.8092 & & \\
\hline
\end{tabular}


Table 17 Well layout

\begin{tabular}{llllll}
\hline MD $(\mathrm{m})$ & TVD $(\mathrm{m})$ & Angle $\left({ }^{\circ}\right)$ & MD $(\mathrm{m})$ & TVD $(\mathrm{m})$ & Angle $\left(^{\circ}\right)$ \\
\hline 450.0 & 450.0 & 0.0 & 665.9 & 634.6 & 82.23 \\
466.9 & 466.9 & 0.0 & 673.4 & 638.5 & 85.58 \\
494.3 & 494.3 & 0.0 & 680.8 & 642.1 & 88.93 \\
521.8 & 521.8 & 1.8 & 688.2 & 645.7 & 92.28 \\
549.2 & 549.2 & 7.2 & 696.1 & 649.8 & 91.28 \\
576.7 & 576.7 & 12.6 & 704.6 & 652.6 & 90.28 \\
581.2 & 580.6 & 18.0 & 713.8 & 655.3 & 90.0 \\
585.5 & 584.0 & 23.4 & 720.9 & 659.4 & 90.0 \\
590.3 & 587.1 & 28.8 & 731.2 & 663.3 & 90.0 \\
594.1 & 590.3 & 34.2 & 743.1 & 666.5 & 90.0 \\
599.5 & 594.2 & 39.6 & 754.3 & 669.8 & 90.0 \\
606.0 & 598.6 & 45.0 & 765.5 & 673.0 & 90.0 \\
610.7 & 601.8 & 50.4 & 776.5 & 675.3 & 90.0 \\
615.5 & 605.3 & 55.8 & 795.2 & 678.6 & 90.0 \\
621.4 & 609.1 & 60.12 & 813.4 & 681.3 & 90.0 \\
626.1 & 611.5 & 62.13 & 837.1 & 682.9 & 90.0 \\
634.9 & 617.5 & 65.48 & 860.7 & 683.7 & 90.0 \\
640.5 & 620.8 & 68.83 & 884.3 & 683.8 & 90.0 \\
647.5 & 624.4 & 72.18 & 907.9 & 683.8 & 90.0 \\
653.3 & 628.0 & 75.53 & 931.5 & 683.8 & \\
658.8 & 631.1 & 78.88 & & & \\
\hline & & & & & \\
\hline
\end{tabular}

Table 18 Well details

\begin{tabular}{lllll}
\hline Bottom MD (m) & ID (in) & Wall thickness (in) & Roughness (in) & Casing ID (in) \\
\hline 577 & 4.89 & 0.29 & 0.001 & 20.00 \\
585 & 4.89 & 0.29 & 0.001 & 20.00 \\
594 & 4.89 & 0.29 & 0.001 & 13.38 \\
606 & 4.89 & 0.29 & 0.001 & 12.25 \\
616 & 4.89 & 0.29 & 0.001 & 12.25 \\
626 & 4.89 & 0.29 & 0.001 & 12.25 \\
640 & 4.89 & 0.50 & 0.001 & 7.00 \\
653 & 4.89 & 0.50 & 0.001 & 7.00 \\
665 & 4.89 & 0.50 & 0.001 & 7.00 \\
688 & 4.89 & 0.50 & 0.001 & 6.00 \\
920 & 4.89 & 0.50 & 0.001 & 6.00 \\
\hline
\end{tabular}

\section{Proxy models of production performance of the field}

See Figs. 14, 15 and 16. 

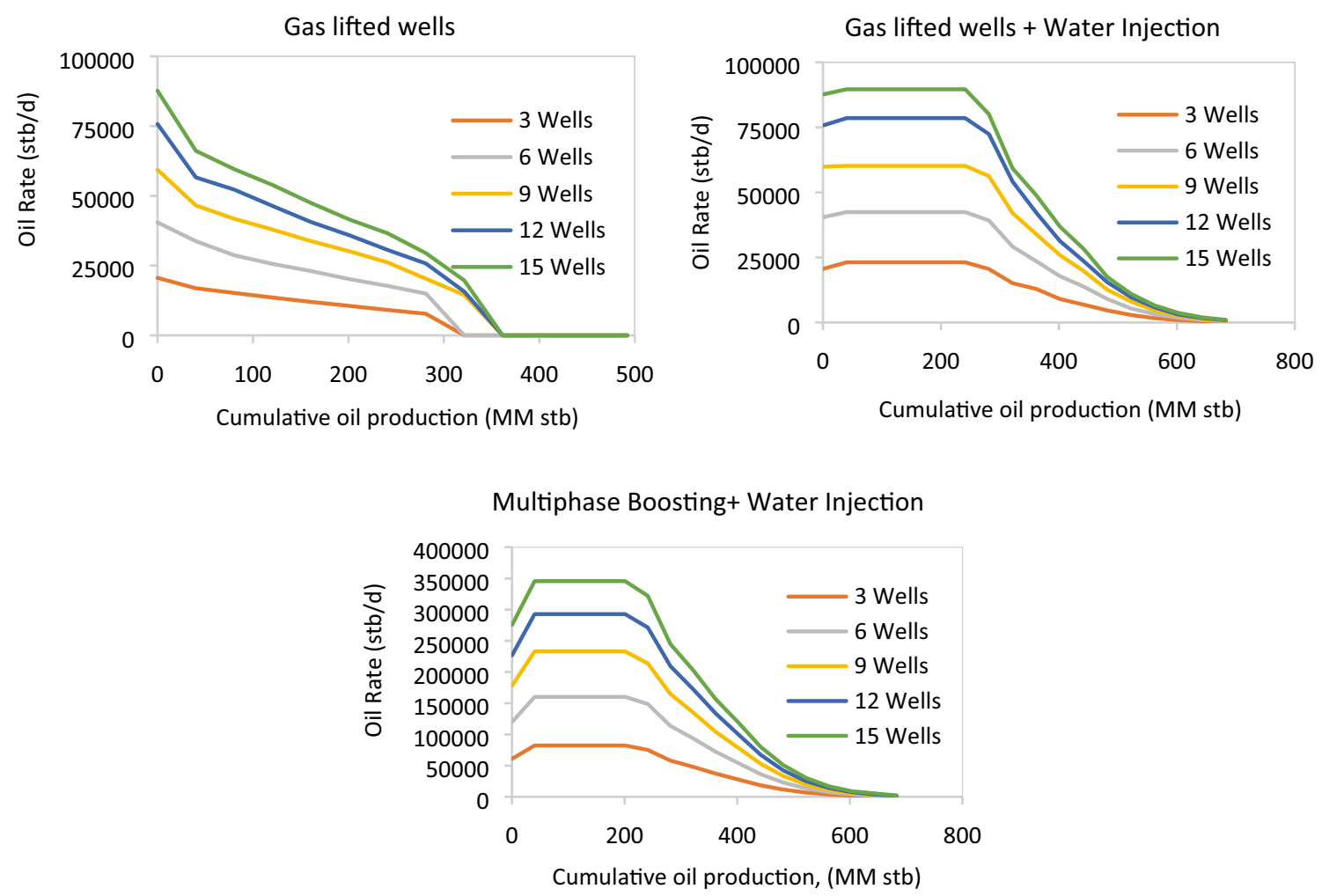

Fig. 14 Potential oil rate for all the recovery scenarios
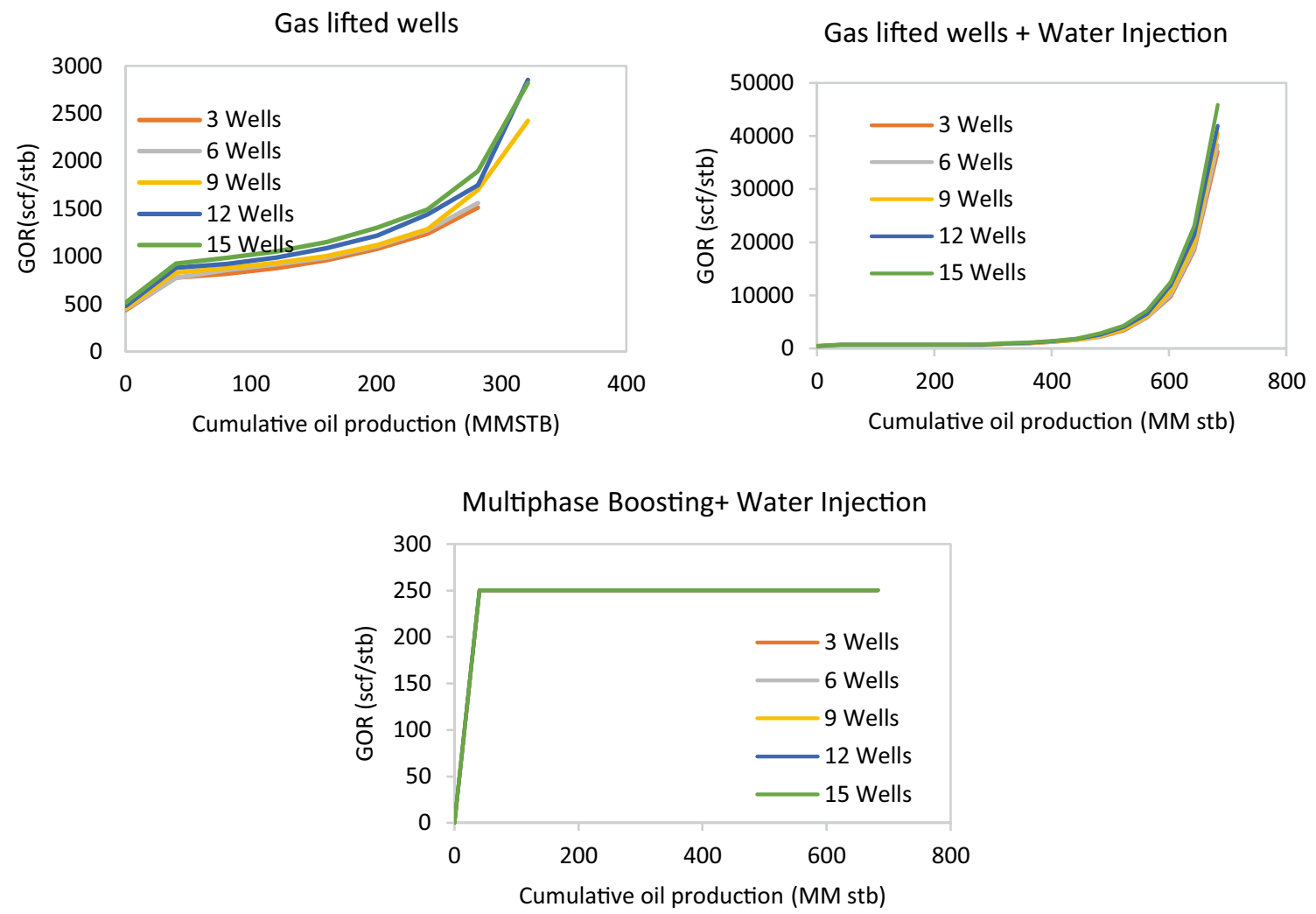

Fig. 15 Potential GOR for all recovery scenarios 

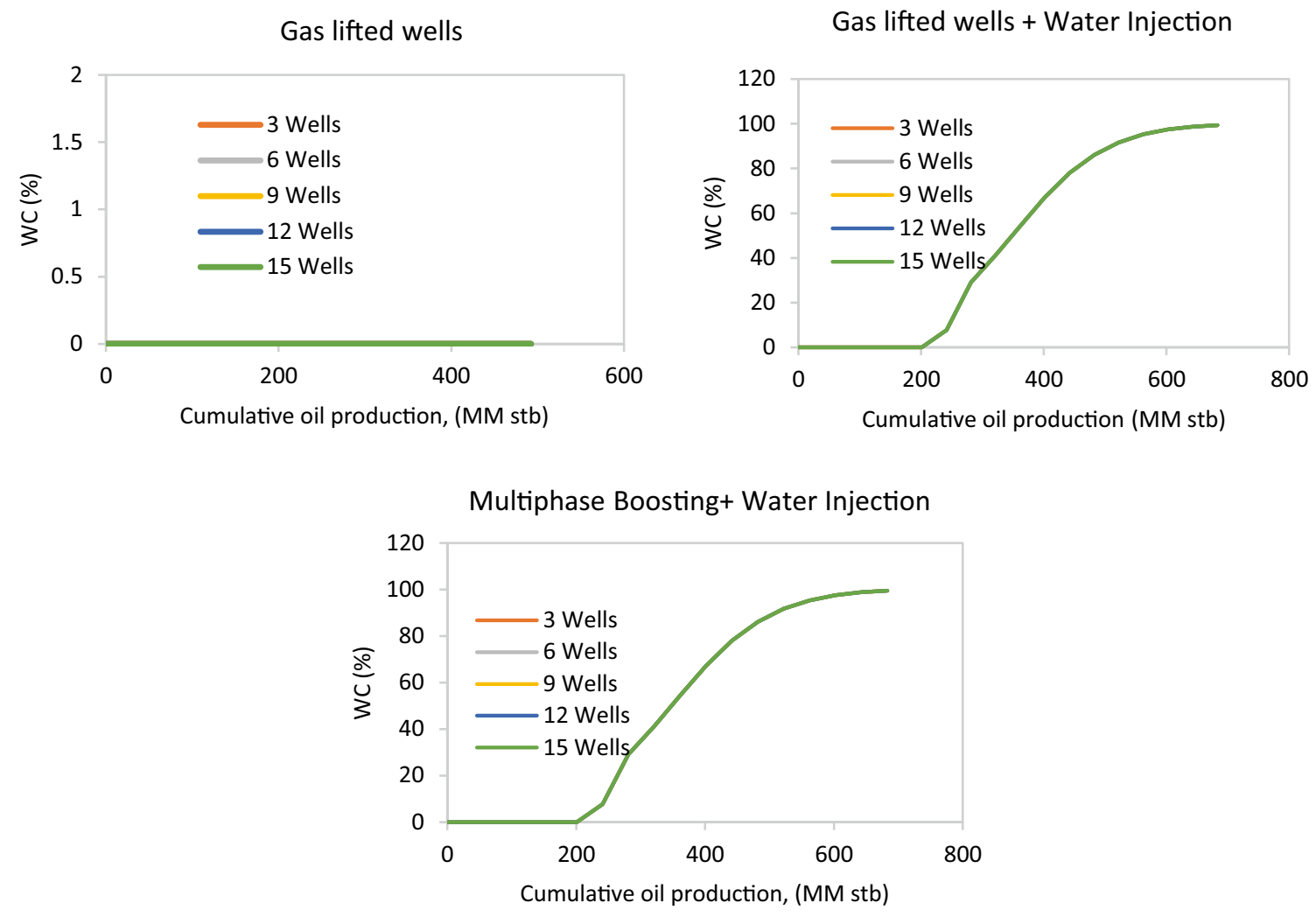

Fig. 16 Potential water cut for all recovery scenarios

\section{Costs proxy model}

TLP:

$$
\begin{aligned}
E_{\text {cap }, \mathrm{TLP}}= & 0.0079 \cdot q_{o}^{\text {capacity }}+29.81 \cdot q_{g}^{\text {capacity }} \\
& +0.0115 \cdot q_{w}^{\text {capacity }}+307.53 \cdot \mathrm{Nw}^{\text {field }}+11702.41 \\
E_{\mathrm{op}, \mathrm{TLP}}= & 6.67 E-4 \cdot q_{o}^{\text {capacity }}+0.8930 \cdot q_{g}^{\text {capacity }} \\
& +2.18 E-4 \cdot q_{w}^{\text {capacity }}+14.01 \cdot \mathrm{Nw}^{\text {field }}+613.93
\end{aligned}
$$

FPSO:

$$
\begin{aligned}
E_{\text {cap,FPSO }}= & 0.0122 \cdot q_{o}^{\text {capacity }}+42.64 \cdot q_{g}^{\text {capacity }} \\
& +0.0173 \cdot q_{w}^{\text {capacity }}+307.87 \cdot \mathrm{Nw}^{\text {field }}+15407.21
\end{aligned}
$$

$$
\begin{aligned}
E_{\mathrm{op}, \mathrm{FPSO}}= & 9.42 E-4 \cdot q_{o}^{\text {capacity }}+1.4050 \cdot q_{g}^{\text {capacity }} \\
& +3.63 E-4 \cdot q_{w}^{\text {capacity }}+14.01 \cdot \mathrm{Nw}^{\text {field }}+613.78
\end{aligned}
$$

Tie-back:

$$
\begin{aligned}
E_{\text {cap,Tie - Back }}= & 0.0366 \cdot q_{o}^{\text {capacity }}+12.74 \cdot q_{g}^{\text {capacity }} \\
& +0.0477 \cdot q_{w}^{\text {capacity }}+369.30 \cdot \mathrm{Nw}^{\text {field }}+21911.58
\end{aligned}
$$

$$
\begin{aligned}
E_{\text {op,Tie - Back }}= & 5.50 E-4 \cdot q_{o}^{\text {capacity }}+0.1245 \cdot q_{g}^{\text {capacity }} \\
& +1.82 E-4 \cdot q_{w}^{\text {capacity }}+14.26 \cdot \mathrm{Nw}^{\text {field }}+349.62
\end{aligned}
$$

DRILLEX (valid for all topside facilities):

$E_{\mathrm{drill}}=253.45 \cdot \mathrm{Nw}_{d, p+i}+1.55 E-11$

\section{Standard error and R-squared for the costs linear regression}

See Table 19.

Table 19 Linear regression statistics for costs equations

\begin{tabular}{lll}
\hline & $\mathrm{SE}$ & R-square \\
\hline $\mathrm{E}_{\text {cap,TLP }}$ & 255.96 & 0.993 \\
$\mathrm{E}_{\text {op,TLP }}$ & 4.57 & 0.999 \\
$\mathrm{E}_{\text {cap,FPSO }}$ & 279.65 & 0.991 \\
$\mathrm{E}_{\text {op,FPSO }}$ & 6.30 & 0.998 \\
$\mathrm{E}_{\text {cap,Tie-back }}$ & 446.37 & 0.990 \\
$\mathrm{E}_{\text {op,Tie-back }}$ & 4.11 & 0999 \\
$\mathrm{E}_{\text {drill }}$ & $3.73 \mathrm{e}-12$ & 1 \\
\hline
\end{tabular}




\section{Water injection table used in the optimization problem}

See Table 20.

Table 20 Cumulative water injection as function of cumulative oil production used in optimization routine

\begin{tabular}{lc}
\hline Np (MMstb) & $\begin{array}{c}\text { Cum_Winj } \\
\text { (MMstb) }\end{array}$ \\
\hline 0.00 & 0.00 \\
40.15 & 43.5439 \\
80.41 & 87.207 \\
120.56 & 130.751 \\
160.71 & 174.295 \\
200.86 & 217.839 \\
241.12 & 264.882 \\
281.27 & 324.912 \\
321.42 & 396.628 \\
361.57 & 488.176 \\
401.83 & 614.036 \\
441.98 & 799.824 \\
482.13 & 1090.96 \\
522.28 & 1580.36 \\
562.54 & 2441.17 \\
602.69 & 4051.35 \\
642.84 & 7250.61 \\
682.99 & 14171.2 \\
\hline &
\end{tabular}

\section{Optimum production rate for study case}

See Figs. 17, 18, 19, 20, 21, 22, 23, 24 and 25.

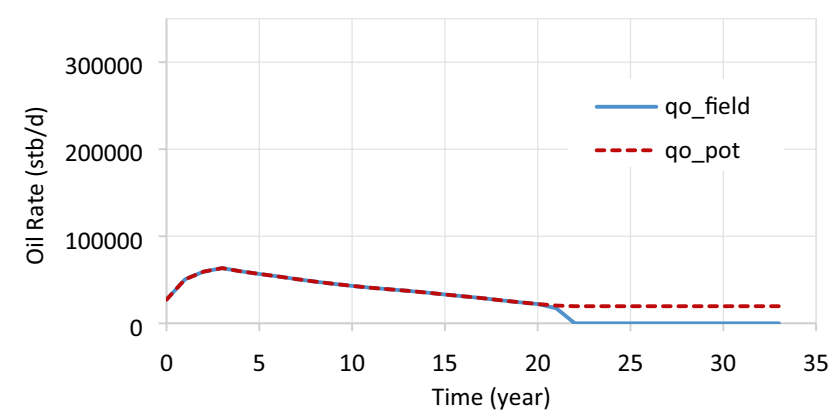

Fig. 17 Optimum oil production profile and oil production potential for strategy TLP with GL

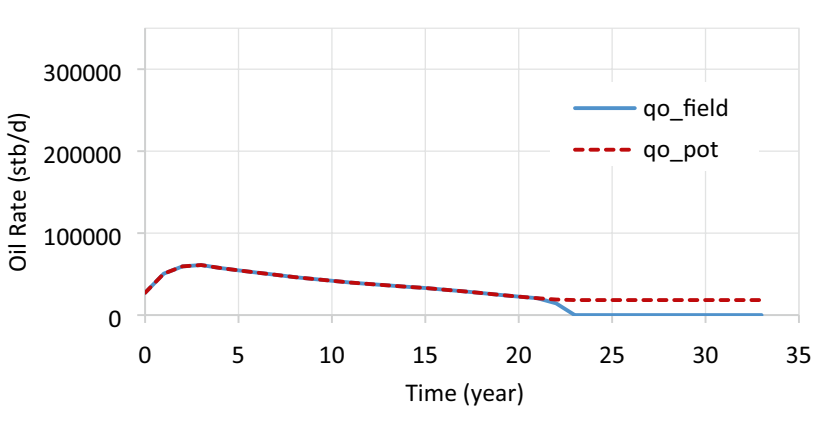

Fig. 18 Optimum oil production profile and oil production potential for strategy FPSO with GL

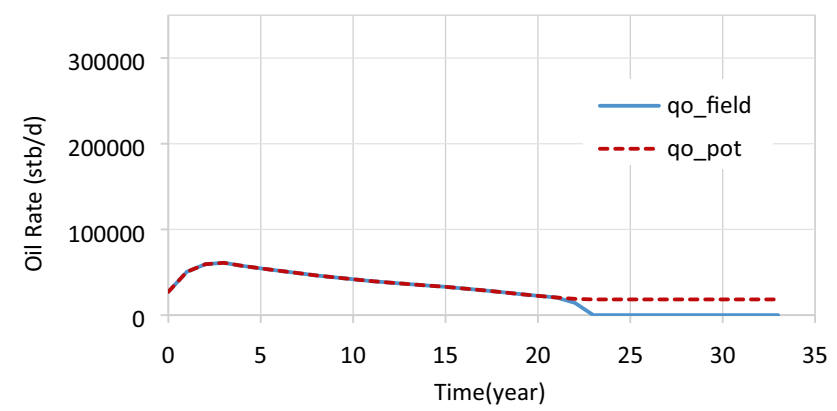

Fig. 19 Optimum oil production profile and oil production potential for strategy Tie-back with GL

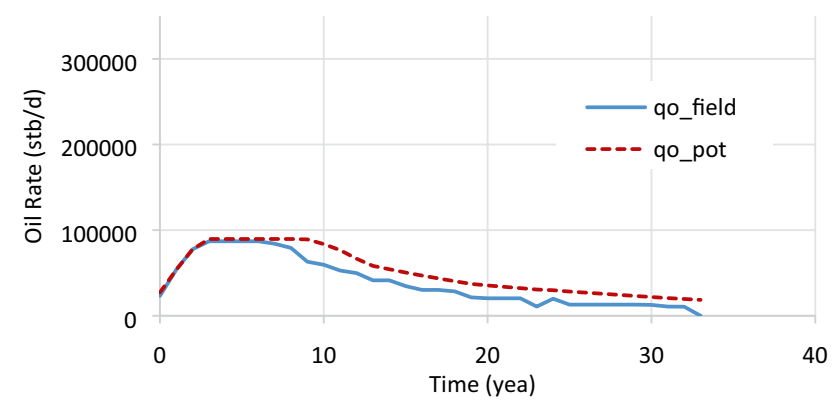

Fig. 20 Optimum oil production profile and oil production potential for strategy TLP with GL + WI

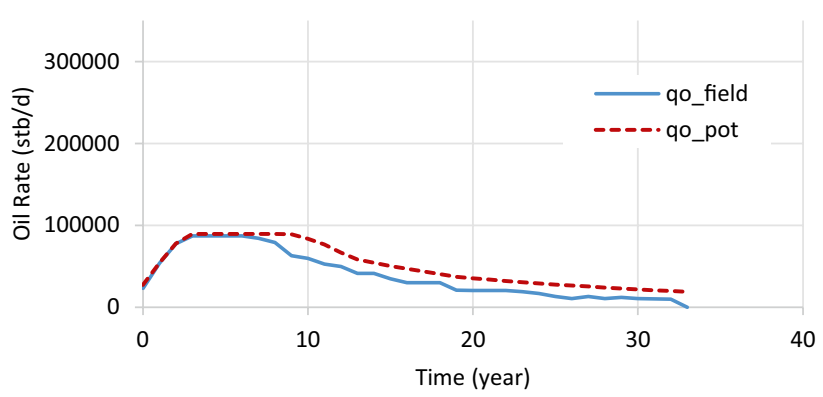

Fig. 21 Optimum oil production profile and oil production potential for strategy FPSO with GL + WI 


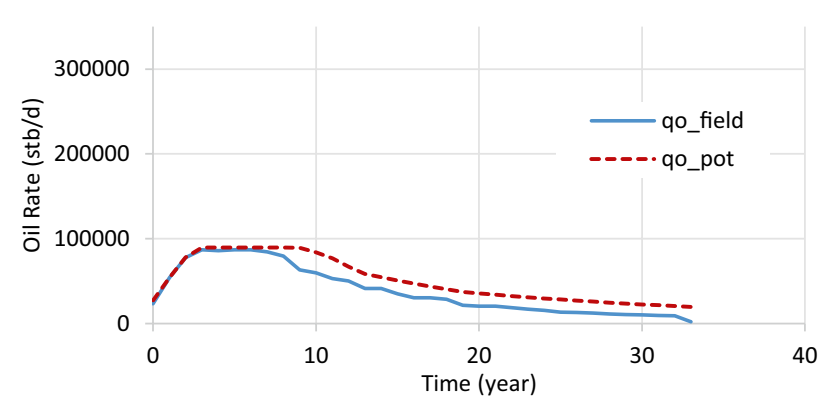

Fig. 22 Optimum oil production profile and oil production potential for strategy Tie-back with GL + WI

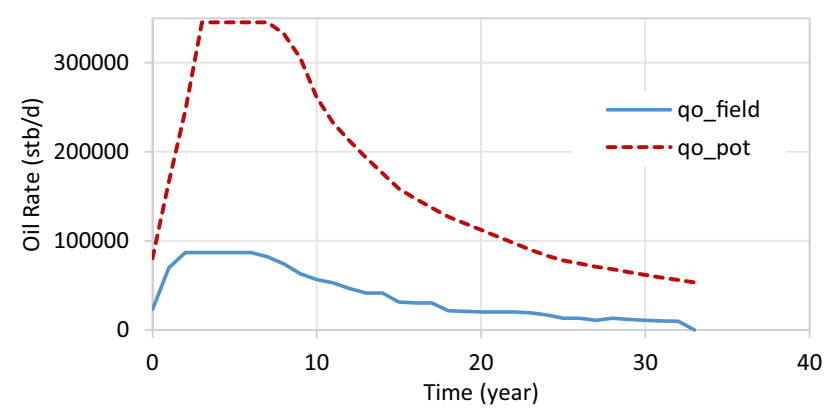

Fig. 23 Optimum oil production profile and oil production potential for strategy TLP with MPB + WI

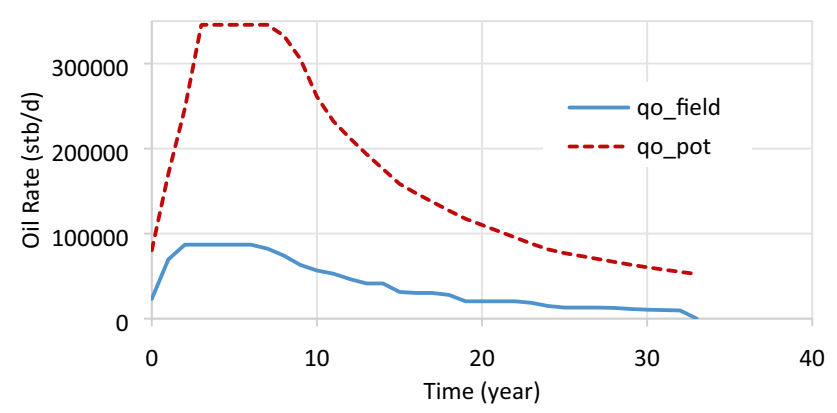

Fig. 24 Optimum oil production profile and oil production potential for strategy FPSO with MPB + WI

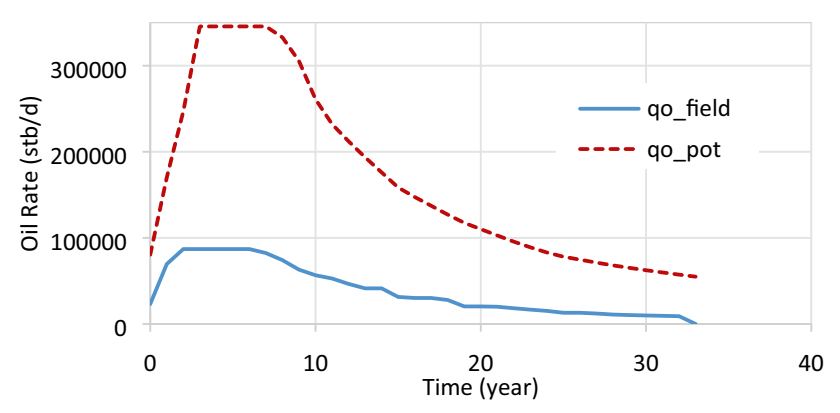

Fig. 25 Optimum oil production profile and oil production potential for strategy Tie-back with MPB + WI

\section{References}

Acona (2018) ACES v5.0

Bellout M, Echeverria Ciaurri D, Durlofsky LJ, Foss B, Kleppe J (2012) Joint optimization of oil well placement and controls. Comput Geosci 16:1061-1079. https://doi.org/10.1007/s1059 6-012-9303-5

Codas A, Campos S, Camponogaram E, Gunnerud V, Sunjerga S (2012) Integrated production optimization of oil fields with pressure and routing constraints: the Urucu field. Comput Chem Eng 46:178-189. https://doi.org/10.1016/j.compchemeng.2012.06.016

Grötschel M, Holland O (1991) Solution of large-scale symmetric travelling salesman problems. Math Program 51:141-202

Hoffmann A, Stanko M (2017) Short-term model-based production optimization of a surface production network with electric submersible pumps using piecewise-linear functions. J Pet Sci Eng 158:570-584. https://doi.org/10.1016/j.petrol.2017.08.063

IBM (2010) IBM ILOG AMPL v12.2-user's guide

Jablonowski CJ, Strachan A (2008) Empirical cost models for TLPs and spars. In: SPE annual technical conference and exhibition. Denver, Colorado, USA, 21-24 September

Jonsbråten T (1998) Oil field optimization under price uncertainty. J Oper Res Soc 49(8):811-818. https://doi.org/10.2307/3009962

Joshi SD (1991) Horizontal well technology. Pennwell Books, Tulsa

Karlik CW (1991) Parametric estimating of oil and gas production facilities capital costs worldwide. In: SPE hydrocarbon economics and evaluation symposium. Dallas, Texas, USA, 11-12 April

Kuznetsov M, Sevastyanova K, Tarasov P, Zilber V, Nekhaev S (2011) Capital cost estimation method for Arctic offshore oil projects. In: SPE Arctic and extreme environments conference \& exhibition. Moscow, Russia, 18-20 October

Litvak ML, Angert PF (2009) Field development optimization applied to giant oil fields. Society of Petroleum Engineers, The Woodlands. https://doi.org/10.2118/118840-MS

Litvak ML, Gane BR, Williams G, Mansfield M, Angert PF et al (2007) Field development optimization technology. Society of Petroleum Engineers, Houston. https://doi.org/10.2118/106426-MS

Litvak ML, Onwunalu JE, Baxter J (2011) Field development optimization with subsurface uncertainties. Society of Petroleum Engineers, Denver. https://doi.org/10.2118/146512-MS

Nazarian B (2002) Integrated field modeling. Ph.D. thesis, NTNU, Norway

Nunes G, Cost AH, de Figueiredo J (2017) An integrated field development methodology for improving FEL1. In: Offshore technology conference Brasil, Rio de Janeriro

Nunes G, da Silva A, Esch L (2018) A cost reduction methodology for offshore projects. In: Offshore technology conference, Texas

Padberg M, Rinaldi G (1991) A branch-and-cut algorithm for the resolution of large-scale symmetric traveling salesman problems. SIAM Rev 33(1):60-100

Petroleum Experts (2016) MBAL, v13.0

Petrostreamz (2018) Pipe-It v 1.8.2

Schlumberger (2012) PIPESIM ${ }^{\circledR}$ v12.02

Schlumberger (2012) PIPESIM 2012.2 open link reference manual

SFI (2019) Center of research-based innovation-NTNU. SUBPRO: subsea production and processing. https://www.ntnu.edu/subpro/. Accessed 3 Nov 2019

Silva TL, Camponogara E (2014) A computational analysis of multidimensional piecewise-linear models with applications to oil production optimization. Eur J Oper Res 232(3):630-642. https ://doi.org/10.1016/j.ejor.2013.07.040

Silva TL, Codas A, Stanko M, Camponogara E, Foss B (2019) Network-constrained production optimization by means of multiple shooting. SPE Reserv Eval Eng. https://doi.org/10.2118/19450 4-PA 
Simonov M, Shubin A, Penigin A, Perets D, Belonogov E, Margarit A (2019) Optimization of oil field development using a surrogate model: case of miscible gas injection. In: SPE reservoir characterization and simulation conference and exhibition, Abu Dhabi, UAE, 17-19 September

Storvold VS (2012) Optimization of investment decisions and production planning in aging offshore petroleum fields. Master thesis, NTNU, Norway

Tupac YJ, Almeida F, Vellasco MMBR (2007) Evolutionary optimization of oil field development. Society of Petroleum Engineers, Houston. https://doi.org/10.2118/107552-MS

Volz R, Burn K, Litvak M, Thakur S, Skvortsov S (2008) Field development optimization of Siberian giant oil field under uncertainties.
In: SPE Russian oil \& gas technical conference and exhibition. Moscow, Russia, 28-30 October

Williams GJJ, Mansfield M, MacDonald DG, Bush MD (2004) Topdown reservoir modelling In: SPE annual technical conference and exhibition, Houston, Texas, USA, 26-29 September

Yadigarov E (2017) Study of development alternatives for remote offshore, low energy reservoirs: the Wisting field case. Master thesis, NTNU, Norway

Publisher's Note Springer Nature remains neutral with regard to jurisdictional claims in published maps and institutional affiliations. 